\title{
Design of intelligent surfaces for energy intensive processing industry
}

\author{
Jeremy R. Smith ${ }^{1,2}$, Jérôme Leveneur ${ }^{1}$, and John V. Kennedy ${ }^{1, *}$ \\ ${ }^{1}$ National Isotope Centre, GNS Science, P O Box 31312, Lower Hutt, 5010, New Zealand \\ ${ }^{2}$ Massey Institute of Food Science \& Technology, Massey University, Palmerston North, New \\ Zealand
}

\begin{abstract}
There are three different factors that can affect adhesion: the process fluid, the processing conditions and the surface of the processing equipment. Of these three factors, the surface properties of the processing equipment are the factor that offers the greatest opportunity for manipulation. The two key surface properties that have been identified to reduce adhesion are the surface energy and the surface topography. The surface energy of a material determines its degree of wettability and, a surface's affinity for water. In previous studies the surface energy of materials have been leveraged in order to create a surface with reduced levels of fouling through surface modification or the addition of polymer coatings with varying degrees of hydrophobicity. In addition, the topography of surfaces has been modified to reduce the level of particle adhesion. These modifications involve creating either a structured or random porous microstructure on the surface. Additional methods identified to reduce fouling include the application of liquid infused porous surfaces at low shear conditions and the use of non-contact heating through techniques such as microwave processing.
\end{abstract}

\section{Introduction}

Stainless steel is one of the most commonly used materials in processing industries due to its strength, corrosive resistance, cleanability and durability [1]. However, stainless steel is prone to fouling due to its relatively high surface energy and hydrophilic nature [2]. In order to combat the effects of fouling, a number of different techniques have been explored to reduce/eliminate adhesion of compounds to a surface. These technologies range from the application of a coating through physical or vapour deposition, doping or electroplating [3]. Two main approaches can be taken to have a positive effect on fouling and cleaning: modification of the energy specific surface properties and the modification of the topographical surface properties [4].

One possibility that presents itself if a durable, corrosive resistant surface modification where stainless steel may be replaced with a lower cost material such as carbon steel [5]. This would have the additional benefit of being able to utilise material with better heat transfer coefficients that may mitigate the effects of any surface coating. However, for a

* Corresponding author: J.Kennedy@gns.cri.nz 
surface modification to be applied to an industrial setting, such as the food industry, it needs to be able to withstand high temperature for short time treatments as well as the intensity of clean in place (CIP) techniques [6]. There is also significant difficulty in comparing reports of different anti-fouling coatings/systems as the experimental conditions vary widely [7].

\section{Surface structure}

The roughness of a surface is generally accepted as one of the main factors affecting adhesion forces between particles and a surface due to the modification of the true area of contact [8]. Having a high level of surface roughness has been identified as enhancing mineral deposition, possibly due to the increase in the number of sites available for nucleation to occur [9]. This suggests that by increasing the smoothness of a surface the level of adhesion and subsequent fouling will be reduced. However, here are conflicting reports regarding whether roughness diminishes or enhances adhesion to a surface. This is likely due to the scale of the roughness, with larger scale roughness promoting adhesion whereas micro-scale roughness can act to reduce adhesion. This is demonstrated in a large number of publications that show that micro/nano scale roughness can result in reductions in adhesion compared to a smooth surface [10].

\subsection{Structured topography}

The majority of surface topographies are controlled at the macro-scale, but not often controlled at the micro and nano scale [11]. As food components exist over a range of length scales, the structure of the solid surface affects the likelihood and extent of fouling. For example, bacteria range in the micrometre size and their surface appendages in the nanometre range, the control of surface topography at these scales could strongly affect bacterial attachment [11]. There are a number of different approaches to create a nano structured surface, from 0D nanoparticles, 1D wires and individual fibres, 2D thin films and 3D fibre assembly [12].

Engineered surface topographies can be achieved using a number of different methods including: nanoimprint lithography, photolithography, [11, 13, 14]. A number of these methods, although very effective at creating structured topographies, are not practical for large scale development of surfaces. Etching has be used to create superhydrophobic stainless steel surfaces [15]. This allows the creation of a surface with the same anticorrosive properties as native stainless steel but with much higher water contact angles (in the $150^{\circ}$ range). The key advantage of being able to create roughness using etching directly on a surface, opposed to adding roughness through deposition techniques, is the inherent stability of the structures formed [15]. As different compounds within a system can vary over a wide range of different sizes, surface topography that contains only one length scale may not be effective as an antifouling material against all of the components in the system [11]. By creating hierarchical topographies, by superimposing small anti-algal topography onto a larger anti-barnacle topography a $97 \%$ reduction in microorganism attachment was identified in a marine setting [16].

Dynamic interactions between proteins and nanoscale surface topographies are complex due to the combination of both attractive and repulsive forces which are a function of the changes in local surface properties [17]. In addition, the flow of fluid over a textured surface may enhance the removal of deposits in comparison with a smooth surface, enhancing the benefits of a structured surface [11]. Graham et al. [18] identified that patterned holes were more effective at reducing attachment of E.coli than linear features under both static and flow conditions. In addition, all structured topographies were found to 
reduce the attachment of E.coli in comparison with a smooth surface, with $1 \mu \mathrm{m}$ patterned holes being found to be the most effective [18].

\subsection{Biomimetic}

Biomimetics is the inspiration of ideas or designs adapted from biology [19]. It involves the understanding of biological functions, structures, design of various materials and principles of objects found in nature [20]. The most discussed biological source for inspiration in the area of antifouling has been the lotus leaf [21, 22]. Other natural sources looked at in regards to antifouling include the pitcher plant, cicada wings, butterfly wings, snail shells, fish scales and shark skin [23].

The lotus leaf has attracted a lot of attention due to its strong water repelling behaviour. This is due to the leaf being a superhydrophobic surface, producing a water contact angle of above $150^{\circ}$ (producing the water beading effect) [24]. The superhydrophobic nature of the leaf is due to its hierarchical surface roughness and the low surface energy epicuticula wax coating the leaf [25], as shown in Figure 1. When water droplets come into contact with the leaf they sit on the apex of the nanostructures as air fills the structure under the droplet [24]. They are considered to be 'self-cleaning' surfaces due to the low contact angle hysteresis of water droplets causing water to roll off the surface whilst taking other particles from the surface [26]. Due to this phenomenon, the term 'lotus effect' is used to refer to surfaces that display superhydrophobic properties. Inspired by the lotus effect, many researchers have sort to mimic the behaviour by creating artificial lotus-like surfaces [27]. However, as these surfaces rely on the trapped air to repel liquids, they tend to fail when the air escapes under conditions involving high temperatures, pressure, humidity and when exposed to low surface tension liquids [28].

Another natured inspired micro-topographical design is the Sharklet AFTM based on the skin of a shark [10]. A sharks skin is made up of tiny scales that are themselves composed of small 'riblets' which are aligned in the direction of fluid flow [11]. The use of the Sharklet design by Schumacher et al. [16] was found to reduce microorganism attachment by $97 \%$, when their hierarchical topography was applied to a marine environment. In their work they also identified a correlation between increasing aspect ratio and a reduction in attachment of bacteria.

As the surface fouling microorganisms in the food and biomedical industry are considerably smaller in size to those in marine applications (typically $1-2 \mu \mathrm{m}$ vs $5-10 \mu \mathrm{m}$ ) research has been conducted using the Sharklet design with these types of microorganisms [11]. The design was applied in the biomedical field to investigate its effect on the biofilm formation of Staphylococcus aureus [30]. Chung et al. [30] found that although the Sharklet design did disrupt the formation of a S.aureus biofilm in comparison with a smooth surface, there were still bacterial cells in the recesses between the design features. Additional work in the biomedical area to investigate the effect of the Sharklet design to reduce microbial contamination has been with E.coli [31]. In this work, Reddy et al. [31] tried a number of modified Sharklet designs to reduce E.coli adhesion and got an average reduction of $47 \%$ in colony forming units (CFUs). However, the question still remains as to whether the Sharklet design is scalable to produce significant antifouling efficiency against the smaller microorganisms present in both the food and biomedical industry [11]. It has been found that superhydrophobic surfaces with hierarchical structures combining the distinct \& complementary roles of microstructure (pressure dissipation) and nanostructure (high capillary pressure) can further decrease contact angle hysteresis and increase pressure tolerance [28]. However, hierarchical topographical features can be difficult to generate, especially at a scale that can be applied to commercial equipment. 


\section{Surface free energy}

The surface free energy of a solid surface is a measure of its intermolecular or interfacial attractive forces [32]. It is the available energy resulting from surface groups, molecules or atoms that are able to interact with other groups, molecules or atoms approaching the surface [33]. The work of adhesion (Wsl) is the work required to separate the liquid from the solid and is equal to the sum of the surface free energy of the solid ( $\mathrm{\gamma s}$ ) and the surface tension (yl) minus the interfacial tension between the solid and the liquid (ysl) [33]:

$$
W_{s l}=\gamma_{s}+\gamma_{l}-\gamma_{s l}
$$

Thus, with lower surface free energy of the solid ( $y s)$, the weaker the adhesion of a particle to the surface [34]. Numerous studies have been conducted investigating the effect of surface energy and adhesion, in particular bacterial adhesion [35]. These studies identified that low energy surfaces have less bacterial adhesion and are easier to clean due to weaker binding at the interface [36]. An optimal range of surface free energy was identified by Baier [37] where adsorption was at a minimum between $22-28 \mathrm{mN} / \mathrm{m}$ [38], as shown in Figure 2.

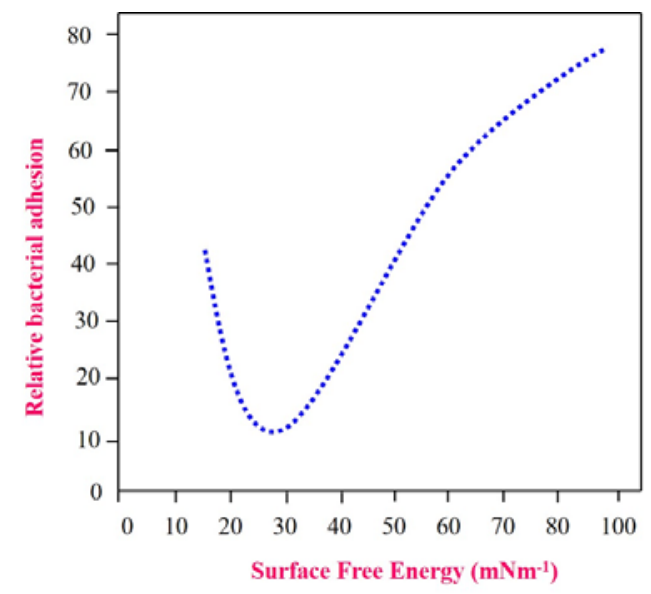

Fig. 1. Effect of surface energy on bacterial attachment.

In this range the adhesive force between the deposits and the surface are at a minimum resulting in either reduced fouling or increased ease of cleaning. This has additionally been demonstrated with mineral deposits [32], backed on tomato deposits [39], cell attachment to a surface [18]. The surface free energy of a material is inversely proportional to its water contact angle [18]. Thus the contact angle can be used as a means to measure the surface free energy of a material [33]. This can be calculated using the equation below [40]:

$$
\gamma_{s}=\gamma_{s l}+\gamma_{l} \cos \theta
$$

Low energy surfaces tend to be hydrophobic, as surface free energy can be used as measure to the degree to which water can be adsorbed to a surface [33]. Metals have high surface energies while polymers tend to have a low surface energy [41]. This is why particles tend to adhere to metallic surfaces more than polymer based surfaces. High surface energy materials are more prone to nucleation and thus have more nucleation sites than lower surface energy materials [42]. It is these nucleation sites that are the starting 
point for mineral adhesion. Changing the surface energy modifies the adhesive forces between deposits and a surface; not the cohesive forces within the deposits [38]. This means that it will have an effect on the interaction between the surface and a potential fouling component, but not on the interaction between the components. As a result, changes to the surface energy can alter the initial onset of adhesion, however, following the initial formation of a fouling layer the subsequent addition to the layer will progress at the same rate as if the fouling rate was on an untreated surface. However, there have also been a number of reports finding both no correlation between cell attachment and surface free energy or finding adhesion is reduced at higher free energies [43]. Therefore to identify the underlying component related to adhesion of material to a surface, the surface energy of a solid was broken down into component parts [44]. This considers the surface energy of a solid is comprised of an apolar Lifshitz-van der Waal component $\left(\mathrm{\gamma}_{2}^{L W}\right)$ and a polar Lewis acid-base component $\left({ }^{A B}\right)$ [43]. The acid-base component consists of an electron donor component $\left(\overline{8}_{2}^{-}\right)$and an electron acceptor component $\left(\mathrm{V}_{2}^{+}\right)$:

$$
\gamma_{2}^{A B}=2 \sqrt{\mathrm{\gamma}_{2}^{+} \mathrm{\gamma}_{2}^{-}}
$$

The electron acceptor component of the surface energy is close to 0 for most solid materials. This suggests that the lower the electron donor component of surface energy, the lower the levels of adhesion. Liu \& Zhao [45] proposed a simple expression to determine the adhesion strength of bacteria that they coined the CQ ratio. The CQ ratio is the apolar Lifshitz-van der Waal component of the solid's surface energy divided by the electron donor component $\left(\mathrm{P}_{2}^{L W} / \mathrm{\gamma}_{2}^{\overline{2}}\right)$ [45]. A strong correlation was found between the total interaction energy of various bacteria in a biofilm and the CQ ratio. In addition, a strong correlation was identified between the CQ ratio and the number of adhering bacterial cells as well as the removal of bacterial cells [45]. In an additional study published in the same year, Liu \& Zhao [43] once again found strong correlations between bacterial adhesion and the CQ ratio, this time on a Ni-P-TiO 2 -PTFE composite material. However, following the two studies conducted in 2011, no further published work related to the CQ value could be found beyond referencing the original experiments.

\section{Wettability}

The wettability of a solid surface is dependent on the interfacial tension at the phase boundary between the surface and what it is in contact with [46]. Wetting is determined by the properties of both the solid surface and the liquid in contact with it [47]. The resulting interaction between the surface and the liquid is determined by the balance of intermolecular forces. Wettability has been identified as a factor that influences fouling, including as a contributing factor in the adhesion of bacteria to a surface [18]. The wettability of a solid surface is related to the surface energy of the surface [41]. There are two possible wetting regimes or states that occur on rough surfaces: the homogeneous Wenzel state and the composite Cassie-Baxter state [20]. The Wenzel model states that a droplet maintains contact with the surface and penetrates the asperities, and the surface contact area is increased [48]. In the Cassie-Baxter model, a droplet is suspended on the asperities thus residing on a composite phase made of both a solid-liquid and liquid-vapour interface [49]. An image depicting each of the models is displayed in Figure 3. 


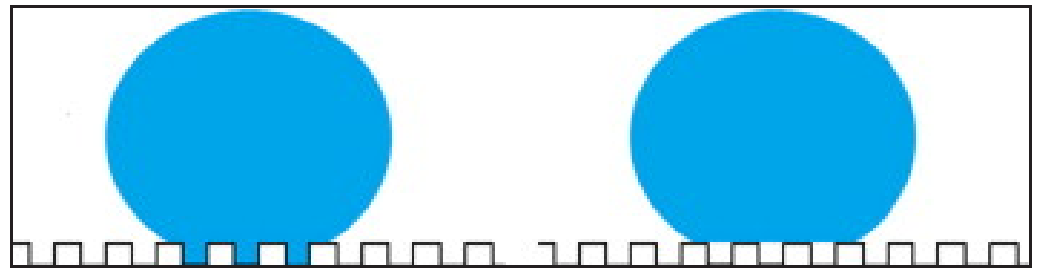

Fig. 2. Wenzel model (left) and Cassie-Baxter model (right) [48].

For complete wetting, the Wenzel model takes into account that the droplet follows the roughened surface and therefore has an equation for the resulting contact angle that takes into account a roughness factor [48]. This finds the contact angle in the Wenzel state to be equal to the contact angle on a smooth surface multiplied by the roughness factor [20]:

$$
\cos \theta=r \cos \theta_{0}
$$

The roughness factor is the actual surface area divided by the planar area [21, 48]. The model predicts that roughness enhances hydrophobicity if $\theta 0$ is greater than $90^{\circ}$, while increasing roughness for surfaces with $\theta 0$ less than $90^{\circ}$ will result in a decrease in the contact angle [20]. In the Cassie-Baxter regime, the contact angle can be calculated using the equation below:

$$
\cos \theta=\varphi_{s}\left(\cos \theta_{0}+1\right)-1
$$

where $\Phi \mathrm{s}$ is the solid fraction in contact with the droplet [50]. Surfaces that are wetted in the Wenzel regime are usually sticky, while those wetted in the Cassie-Baxter regime tend to be slippery [48].

\subsection{Super hydrophobic surfaces}

Hydrophobic surfaces can be enhanced to become super hydrophobic by modifying the surface by means of the addition of roughness or more accurately by adding a certain type of morphology [48]. A super hydrophobic surface is a solid surface that when in contact with water produces a contact angle of greater than $150^{\circ}$ [51]. They can work to limit/prevent adhesion as water is neither adsorbed or does not spread over the surface, so the water dynamics of the flowing system keep the underlying surface clean by sweeping away solid material [52]. This ability of fluid flow to sweep away particles from the surface is referred to as self-cleaning [53]. The two main requirements for a super-hydrophobic surface are that the surface should be hydrophobic, and hence have a low surface energy, and they should also be rough [54]. There are two conventional ways to produce a superhydrophobic surface: creating a rough structure on a hydrophobic surface and the other is by modifying rough surfaces with low surface free energy materials [55]. The same techniques utilised in the fabrication of micro and nanostructures are used in the production of super-hydrophobic surfaces, namely lithography, etching, deposition and self-assembly [54].

A number of factors affect the ability of these super hydrophobic surfaces to prevent adhesion from occurring. These factors are related to the conditions to which the surfaces are exposed to. This is due to these surfaces relying on air as a lubricating fluid which can fail when the air escapes under conditions involving high temperatures, pressure, humidity and when exposed to low surface tension liquids [28]. In addition, the fluid flow conditions also play an important role, as a surface that is super-hydrophobic that can reduce bacteria adhesion when there are flow conditions; however, in stagnant conditions they may promote surface adhesion [56]. As discussed earlier in the report, the Lotus leaf was one of the initial inspirations for researchers to look at wettability to reduce particle adhesion due 
to its super-hydrophobic properties [24]. From this inspiration, a wide range of superhydrophobic surfaces have been created to investigate their antifouling properties. Examples include clusters of carbon nanotubes (CNTs) which have been shown to produce good super-hydrophobic surfaces as they provide substantial surface roughness, strength, thermal conductivity and flexibility [52]. Additionally, by creating roughness on a hydrophobic polysiloxane surface the water contact angle was found to increase from $75^{\circ}$ to $169^{\circ}$, making the surface a super-hydrophobic surface [57].

\subsection{Super hydrophilic surfaces}

A super hydrophilic surface produces a contact angle of less than $5^{\circ}$ when water is brought into contact with it [52]. The super hydrophilic surface works by forming a hydration layer on the surface [52]. The hydration layer also known as the "lubricating liquid film" or "water shield" lessens the attractive electrostatic interactions between foulants [58]. The hydration layer acts to provide a barrier between the potential fouling compounds and the surface. Examples of this includes water attracting nano-composites surfaces with a $\mathrm{TiO}_{2}$ coating [52]. In the work of Yoon \& co-workers [52] they found that highly uniform coating was produced with the creation of tiny structures around groups of agglomerated $\mathrm{TiO}_{2}$ allowing water to instantly spread onto the surface. This is caused by capillary effects and the water surface tension, resulting in a tightly bound layer of water near the super hdrophilic surface [59].

In an experiment conducted using E.coli as an adhesive substrate, it was found that in stagnant conditions a super hydrophilic $\mathrm{TiO}_{2}$ coating was superior to a superhydrophobic carbon nanotube/PTFE coated system in limiting adsorption of the bacteria [52]. However, the opposite trend was exhibited in flowing conditions, where the shear exerted by the flowing fluid caused the super hydrophobic surface to have a superior performance. This is likely to be down to the effect of shear at the interface of the solid/liquid. As the shear increases there will be a greater force acting on any solids on the hydrophobic surface, pushing them along and conforming to its 'self-cleaning' properties under shear. However, the super hydrophilic, which relies on an aqueous layer between the surface and the rest of the process fluid, in the higher shear environment will reduce the thickness of this layer and hence reduce its effectiveness at preventing adhesion. This indicates the importance of the flow conditions on the adhesion of particles to a surface. The results caused the authors to suggest that a hybrid system could be considered in order to be implemented throughout an entire processing system where there is both stagnant and flow conditions.

\subsection{Amphiphilic material}

An amphiphilic material is one that contains both hydrophilic and hydrophobic regions. The development of surfaces that contain both hydrophobic and hydrophilic components so that they exhibit both anti-fouling and fouling release properties[7]. The intrinsic incompatibility between the hydrophobic and hydrophilic components results in phase segregation which leads to compositional, morphological and topographical surface heterogeneity, which makes the interaction between biomolecules and a surface energetically unfavourable [60]. Amphiphilic materials have been found to be effective at preventing the adsorption of a range of proteins [60,61] as well as exhibiting antibiofouling characteristics [62]. These surfaces have been particularly applied to investigations surrounding marine related fouling. Examples of amphiphilic materials included: branched fluro-polymers with polyethylene glycol (PEG) chains [62, 63]; perfluroethylene and PEG [64]; polysolfone-graft- poly (ethylene glycol) methyl ether methacrylate [65]. One issue is that many of these materials contain fluro-polymers that are 
present in the form of long perfluroalkyl chains, which can degrade to form toxic perfluroalkyl acids [7]. Therefore alternative compounds would need to be utilised if amphiphilic surfaces are to be applied to the food industry.

\section{Coating systems}

The basic idea behind coating systems is to provide a barrier layer between the surface of the equipment and the processing environment. In addition, the coating can provide a 'new' surface with a lower surface energy or enhanced smoothness that can act to reduce the adhesion of fouling compounds. One issue with the application of a coating layer to heat transfer equipment, such as heat exchanges, is that the coatings tend to have a lower thermal conductivity and thus reduces the overall heat transfer coefficient. However, as fouling layers tend to have a similar effect in reducing the heat transfer coefficient, the use of a coating layer generally provides a higher overall heat transfer coefficient over the duration of processing compared to the progressive reductions as a result of fouling.

\subsection{Polymer coatings}

Polymers have been used to coat processing equipment to mitigate fouling by reducing the adhesion of compounds to surfaces. Polymers tend to have a low surface energy [41] and be hydrophobic in nature. The low surface energy of these polymers is likely to be the reason for their ability to reduce the level of particle adhesion on a surface [34]. A number of different polymers have been utilised as a coating material including, Perfluoroalkoxy (PFA) [66], Polyetheretherketone (PEEK) [2], polydimethylsiloxane (PDMS) [67] and polyurethane [68]. These polymer coatings have been applied to a range of different surfaces and equipment to investigate the fouling of a number of different food related compounds. Low energy polymer coatings were found to have a reduced level of starch adhesion than stainless steel [2]. Polymer coatings have also been identified as being able to limit mineral adhesion on heat exchangers [69]. In addition, polymer coatings have been found to be effective at reducing bacterial adhesion to a processing surface $[70,71]$. Many of these polymer coatings have also been identified as having an enhanced cleanability in contrast with stainless steel [2]. However, the most common polymer for antifouling coatings is PTFE.

\subsection{PTFE \& composites}

Polytetrafloroethylene or PTFE is a widely used solid lubricant [72]. A possible reason for the low friction of PTFE is the long chains, $-\left(\mathrm{CF}_{2}-\mathrm{CF}_{2}\right)$-, which orient on the transfer surface during sliding, resulting in a low shear-strength interface with the bulk surface on which the PTFE is coated [72]. Due to the molecular arrangement of PTFE, with its $13 / 1$ or $15 / 1$ helical structure, the fluorine atoms are close together and form a smooth cylindrical surface which molecules can easily slide against [73]. Kananeh et al.[46] investigated the effect of various coatings on whey protein adsorption to plate heat exchangers. They identified that PTFE resulted in a greater degree of adhesion but had a significant reduction in CIP time, whereas polyurethane coatings reduced adhesion and reduced cleaning (CIP) time, although not to the same degree as PTFE. One key drawback with the use of PTFE as a coating system is that it has poor wear resistance [72, 74]. In order to improve PTFE's ability to withstand wear, filler particles are often added to the PTFE matrix [74]. A number of different PTFE based composites are outlined in the sections below. 


\subsubsection{Ni-P-PTFE}

A promising technique to reduce fouling is the use of electroless nickel (EN) deposition with embedded PTFE particles [4, 75]. The application of a Ni-P-PTFE coating is achieved through an autocatolytic plating process [76]. This involves the incorporation of PTFE nanoparticles into the Ni-P matrix acquiring advantages of properties of both materials [32]. As this coating is metal based with only a small percentage of PTFE, the thermal conductivity is only slightly lower than stainless steel making it suitable for applications involving heat transfer [45].

Ni-P-PTFE has been found to be an effective coating in the reduction of fouling during milk processing. Barish \& Goddard [4] found a $96 \%$ reduction in the accumulation of fouling on plate heat exchangers used to process raw milk at $85^{\circ} \mathrm{C}$ over an 8 hour period, in comparison with stainless steel. One of the most significant alterations to the surface is in regards to the surface energy, with stainless steel having an energy of $41.44 \mathrm{mN} / \mathrm{m}$ compared with the Ni-P-PTFE coating of $24.69 \mathrm{mN} / \mathrm{m} \mathrm{[4].} \mathrm{Over} \mathrm{the} 8$ hours of processing, the Ni-P-PTFE coated heat exchanger was identified as having a reduction in the heat transfer coefficient of less than $10 \%$ while the standard stainless steel heat exchanger had a reduction in the heat transfer coefficient of close to $70 \%$. The harsh conditions of the CIP process were found to influence the surface composition of EN-PTFE, in particular the acid used was found to cause a decrease in the fluorine concentration after completing 6 cycles [6]. However, the alkali sanitizer, although found to reduce the fluorine over extended periods of time, did not lose its hydrophobicity, surface energy and roughness, hence retaining its anti-fouling character [4]. These authors stated that acid may not be needed in the cleaning of modified surfaces as its main job is to remove any inorganic fouling which may not accumulate on the modified surface.

\subsubsection{Ni-Cu-P-PTFE}

The addition of copper to Ni-P-PTFE aids in improving the corrosive resistance of the material [77]. As with other PTFE composites, the increasing content of PTFE in the material was found to decrease the surface free energy of the composite [32]. In the work of Zhao et al. [32] where a Ni-Cu-P-PTFE coating was utilised to investigate adhesion of both bacteria and calcium sulphate, the adhesion of both substances showed a direct link with surface free energy following the Baier curve. One interesting observation that was made in this work was that the structure of the calcium sulphate differed significantly on the stainless steel and the low surface energy material. Instead of the usual densely packed structure, the low surface energy Ni-Cu-P-PTFE had a loose porous deposit of calcium sulphate.

\subsubsection{CNT-PTFE}

The use of carbon nanotubes as a coating material is somewhat limited due to their high degree of wear [46]. However, the addition of CNT's to a matrix such as PTFE can create a nano composite material that has improved properties. The use of both ultrasonication and annealing assist in the uniform distribution of CNT nano particles into a PTFE matrix, which produces a composite that has a high level of wear resistance and is also nonwettable [78]. Increasing the percentage of CNT in the matrix was found to decrease the friction coefficient, suggesting the CNTs can be self-lubricating [79].

A CNT-PTFE nanocomposite surface was found to have weaker attachment for protein nucleation than both PTFE and uncoated stainless steel [46]. The weaker attachment allowed the shear exerted by the flowing milk to sweep away protein molecules from the 
surface, resulting in a reduction in the nucleation rate and reduced level of fouling. Kananeh et al. [46] found that over 5 hours of pasteurisation, the CNT-PTFE coating reduced the energy consumption by $10.2 \%$ due to the reduced level of protein accumulation on the surface of the heat exchanger. In addition, due to the reduction in accumulation, it is possible that the production runs could be extended as a result so that there is a reduction of down time during CIP. CNT-PTFE has been identified as an effective anti-fouling coating in regards to bacterial adhesion [80]. This was in the form of reducing bacterial (E.coli) adhesion in flowing conditions, as it produced a superhydrophobic surface that was in effect self-cleaning [52]. However, when the same surface coating was used in stagnant conditions the reduction in bacterial adhesion in comparison to stainless steel was much lower than in flow conditions (25\% reduction compared to $\sim 80 \%$ ) [80].

The incorporation of PTFE nanoparticles into a silver coating has been done to incorporate the antibacterial properties of silver with the non-stick properties of PTFE [81]. It was found in this work that by increasing the content of PTFE nanoparticles in the silver coating reduced the surface energy and as a result reduced the level of E.coli cells adhering to the surface. In addition, Zhao et al. [81] found that the Ag-PTFE coatings had a greater level of corrosion resistance than stainless steel 316L.

\subsection{Hydrophilic polymers}

Hydrophilic polymers have been used as coatings to reduce the adhesion of fouling material [7]. As discussed earlier, the common properties of these polymers include their hydrophilic nature, electrical neutrality and being hydrogen bond acceptors (not donors) [82, 83]. The polymers can be applied as a simple coating to surfaces or grafted onto a surface in the form of polymer brushes [7].

The key factor that results in the reduction of fouling on hydrophilic polymers is the strong association with water molecules that can result in a hydration layer. The association with water can provide a barrier for fouling material and lessens the attractive electrostatic interactions between foulants [58]. This, in combination with the application of the polymer as a coating or in brush form, can act to reduce the formation of a fouling layer. As proteins tend to preferentially adsorb onto hydrophobic surfaces such as stainless steel, the creation of surfaces with a hydrophilic nature can act to reduce protein related fouling [7]. The reduction in protein fouling has been the primary application of hydrophilic polymers in experimental work conducted. One of the most common hydrophilic polymers that is used to resist protein adsorption is polyethylene glycol, or PEG as it is often referred to. Immobilizing PEG is a common method in producing a surface that resists the adhesion of proteins [67]. The mechanism preventing protein adsorption to PEG is still not understood in detail, however, the main reason is due to the strong association, through hydrogen bonding, between PEG and water leading to an excluded volume effect making protein adsorption unfavourable [84]. In addition, PEG brushes have been found to provide a steric barrier preventing compounds coming in contact with the surface, preventing adhesion [85]. A issue with the use of PEG is that it is susceptible to oxidation which leads to a reduction in its adsorption resistance over time [86].

\subsection{Zwitterionic polymers}

Although many hydrophilic surfaces can prevent/reduce non-specific protein adsorption, they are often not capable of preventing the adhesion of other compounds such as bacteria [87]. Zwitterionic polymers are defined as ampholytic polymers where ionic groups of opposite charges form a part of the same pendant groups [88]. Zwitterionic polymers were inspired by the anti-biofouling properties of blood cell membranes [70]. Despite having 
charged groups, zwitterionic compounds have an overall neutral charge [89]. In studies comparing zwitterionic polymers with hydrophilic polymers, such as PEG, comparable results have been found related to protein adsorption [7, 90]. Zwitterionic materials that have been used as anti-fouling coatings include phosphobetaine, sulfobetaine and carboxybetaine [89].

The hydration of zwitterionic polymers is critical to their ability to repel proteins as the hydration layer generates the repulsive force [7]. Unlike PEG, zwitterionic polymers bind to water electrostatically as a result of ionic interactions [91]. The electrostatic binding of water to the surface is stronger than that which occurs on the hydrophilic polymer coating [91]. This high water-binding capacity allows for the formation of a highly hydrated surface which is key to zwitterionic material having anti-fouling properties [89].

As with the hydrophilic polymers the surface grafting density and chain length determine the zwitterionic polymers resistance to protein adhesion [7].

\subsection{Electroless plating}

In addition to its use with PTFE nanoparticles (as discussed above), electroless plating can be applied in other anti-fouling coatings. Electroless plating is a chemical reduction of a metallic ion in a solution containing a reducing agent, and the ensuing deposition of the metal without electrical energy [92]. The incorporation of $\mathrm{TiO}_{2}$ nanoparticles into the electroless plated Ni-P matrix has been identified as a means of increasing the hardness, corrosion resistance [93] and wear resistance of the coating [94]. The production of an electroless plating of $\mathrm{Ni}-\mathrm{P}-\mathrm{TiO}_{2}$ on stainless steel was found to have anti-adhesion properties when tested with three different strains of bacteria, after exposure to UV light [95]. In this work, Zhao et al. [95] incorporated titanium dioxide nanoparticles at a number of different levels into the Ni-P matrix, identifying that adhesion reduced as the percentage of $\mathrm{TiO}_{2}$ in the composite increased. This decrease in adhesion was found to correlate with an increase in electron donor component of surface energy. The use of UV light on the $\mathrm{TiO}_{2}$ prior to bacterial adhesion testing was due to the microbiocidal effect due to a photocatalytic reaction produced when $\mathrm{TiO}_{2}$ is exposed to wavelengths of light below 385 $\mathrm{nm}$ [96]. This work stems from that done on bacterial adhesion on $\mathrm{TiO}_{2}$, which found that pre-exposure to UV light caused $\mathrm{TiO}_{2}$ to temporarily become a superhydrophilic substance (dropping the water contact angle from 59 to $0^{\circ}$ ) and reduced bacterial adhesion to the surface [97]. When this was applied to the Ni-P-TiO $\mathrm{T}_{2}$ composite, the use of UV was also found to reduce the water contact angle from 52 to $40^{\circ}$, and as a result making the surface more hydrophilic [95].

An additional surface coating trialled using electroless Ni-P is Ni-P-BN, which was used to investigate its ability to restrict mineral deposit formation [98]. In this work, Al-Janabi et al. [98] found that Ni-P-BN reduced the rate and amount of calcium sulphate deposition in comparison to a number of different coatings and stainless steel. The authors evaluated the fouling rate with a number of different components of the interaction energy, finding that the Ni-P-BN to have the lowest van der Waal component but the highest electron donor component. The Ni-P-BN coating was found to exhibit a degree of corrosion following the cleaning of the surface [98].

\subsection{Antimicrobial coatings}

Antimicrobial surfaces can prevent the formation of biofilms by either acting to repel microbes or kill those in the vicinity of the surface [99]. The latter, active antimicrobial materials incorporate physically entrapped or covalently immobilised antimicrobial agents [100]. These materials utilise the diffusion of the antimicrobial agent out of the matrix as a 
dispersion mechanism. A number of different antimicrobials have been incorporated into the matrix of these antimicrobial materials including silver [101], antibiotics [102], covalently coupled quaternary ammonium [103] and nitric oxide [104]. Although these materials often perform relatively well, they are often hindered by their limited lifetime resulting from the mechanism responsible for their antimicrobial action [100]. Another approach, avoiding the limited life of antimicrobial coatings, is to implant the silver ions into the metal surface.

Another approach is to develop antimicrobial surfaces that kill bacteria on contact; not releasing biocides and thus not exhausting the antimicrobial properties [99]. These contact active antimicrobial surfaces can be created using antimicrobial polymers attached to the processing surface [105]. There are two approaches of achieving this: polymeric biocides, biocidal groups attached to a polymer backbone, and biocidal polymers [99]. Polymeric biocides are small repeating units of biocidal groups attached to a polymer. Biocidal polymers such as polycationic antimicrobial polymers work by disrupting the outer membrane of the cell, causing cell lysis to occur resulting in cell death [99]. Examples of antimicrobial polycations that are used include quaternary ammonium and phosphonium.

\section{Ion implantation}

Ion implantation is the introduction of atoms into surface of a solid material via the bombardment with ions in the $\mathrm{keV}$ to $\mathrm{MeV}$ energy range [106]. As the ions only penetrate the uppermost layers of the surface, the surface properties can be modified whilst the bulk properties remain the same [107]. As a surface alloy is created, there are no issues regarding adhesion such as in chemical vapour deposition (CVD) [76]. The local environment of a particle on the surface of a solid differs from that of particles within the solid [108]. This is due to interior particles experiencing a uniform force from all sides, while for the particles at the surface an unsaturated force field exists. As a result, there is a tendency for the surface particles to be pulled into the solids interior in order to reduce the surface area with a consequence of producing surface tension.

The Electric Double Layer theory states that if an element with weak metal properties (e.g. $\mathrm{F}, \mathrm{H}, \mathrm{Si}, \mathrm{C} . .$.$) is implanted into a surface; both the free electrons on the surface and the$ surface energy will be reduced [109]. In addition, the dose and ion implantation energy both have a significant effect on the surface energy and adhesion of the modified surface [108]. Unlike a number of different surface modification techniques, ion implantation does not have a significant effect on the overall heat transfer coefficient [110]. This is due to the ions being embedded in the surface of the material and only a few atoms thick. The implantation of $\mathrm{N}^{+}, \mathrm{O}^{+}$and $\mathrm{SiF}_{3}{ }^{+}$were evaluated in regards to their effect on the adhesion of two different strains of bacteria [111]. All of the implanted surfaces outperformed native stainless steel. They were found to have a lower surface energy, increased water contact angle and had a decreased level of roughness. In this work, Zhao et al. [111] found lower bacterial adhesion with stainless steel surfaces that had $\mathrm{SiF}_{3}{ }^{+}$implanted in comparison to those with $\mathrm{N}^{+}$and $\mathrm{O}^{+}$. Over a time frame of 24 hours, the adhesion to the $\mathrm{SiF}_{3}{ }^{+}$implanted surface remained statistically significantly lower than native stainless steel for both bacterial strains. Although a significant difference was identified for the adhesion of one bacterial strain to the $\mathrm{N}^{+}, \mathrm{O}^{+}$implanted surfaces; no statistically significant difference was identified for the other strain compared to native stainless steel.

The implantation of $\mathrm{SiF}_{4}$ into stainless steel was found to result in a significant reduction in $\mathrm{CaSO}_{4}$ deposits forming in pool boiling experiments [108]. Additional work done investigating ion implantation and its effect on mineral fouling mitigation includes the work of Nejim et al. [110]. In their work they investigated the effect of Si, F \& H ions implanted into stainless steel to reduce the adhesion of $\mathrm{CaSO}_{4}$. It was found that all three surfaces 
reduced the amount of mineral deposits significantly compared to untreated stainless steel. Out of the three modified surfaces the F implanted surface had superior performance to the others [110]. This benefit in the reduction in $\mathrm{CaSO}_{4}$ deposits manifested in a final heat transfer coefficient of up to $120 \%$ greater than the control surface, following 50 hours of pool boiling.

Buef et al. [112] in their comparison of various surface modification techniques found that the implantation of $\mathrm{SiF}^{+}$was the best performer in reducing adhesion. However, the reduction from native stainless steel was only $18 \%$ and little difference in adhesion was identified between stainless steel and the $\mathrm{SiF}^{+}$following cleaning. In the same experiment $\mathrm{MoS}_{2}$ was implanted into a surface by Beuf et al. [112], and although there was a slight reduction in adhesion compared to stainless steel, it was a smaller reduction than the $\mathrm{SiF}^{+}$ sample. The use of antimicrobial compounds, such as silver ions, have been used to try and prevent biofilm formation [113]. Dhillon [107] investigating the effect of $\mathrm{Ag}$ ion implantation on bacterial adhesion and biofilm formation. This work identified that although the Ag ions had an antimicrobial effect; bacteria could still bind to a conditioning film of protein or were protected by EPS, reducing the effect of the surface modification. The key drawback in regards to the use of ion implantation is the high capital and operating costs associated with the technique [76].

\section{Physical vapour deposits}

Physical vapour deposition (PVD) is a form of vacuum deposition involving physical processes to deposit thin coatings via the condensation of a vaporised form of a solid precursor [114]. There are a number of varieties of PVD, including: cathodic arc deposition, electron beam, thermal evaporation deposition, pulsed laser deposition and sputtering deposition [114]. The key drawback associated with PVD methods are the low deposition rate, however, this was circumvented with the development of magnetron sputtering [114]. This involves the addition of magnets to the cathode resulting in the trapping of a greater quantity of electrons just above it, producing a higher ionization yield.

\subsection{Sputtering}

Sputtering coating is a physical vapour deposition (PVD) process occurring at subatmospheric pressures [76]. The high voltage that is applied between the surface and the coating material ionises the gas in the chamber until a plasma is ignited [76]. Sputtering deposition uses a glow discharge plasma to deposit conductive coatings on a surface via the ion bombardment of a metal [114]. The advantages of using sputtering coatings is the development of hard and very adhesive films [76].

TiN was used as a surface coating to investigate its effect at reducing adhesion of calcium phosphate before and after cleaning $[115,116]$. In the experiment, Rosmaninho et al. [116] used sputtering to apply a coating on a stainless steel surface, with different proportions of $\mathrm{Ti}$ and $\mathrm{N}$ giving the surfaces a different electron donor component of surface free energy $\left(\gamma^{-}\right)$. In their testing conditions they found that surfaces with lower $\gamma^{-}$, deposition started at a slower rate and reached a lower amount than the higher $\gamma$ - surfaces. Rosmaninho et al. [116] found that all of their TiN surfaces retained lower quantities of mineral deposits after cleaning than stainless steel and those with lower $z$ - values had a lower mass of deposits remaining. The titanium content was found to influence the $\gamma$ - value, with the samples with the lowest quantity of titanium having the lower values of $\mathrm{\gamma}$-. In addition, Rosmaninho et al. [115] found an exponential growth curve associated between the particle adhesion coefficient and $\gamma^{-}$-values, with the lower $\gamma^{-}$-values having the lowest particle adhesion coefficient. 


\subsection{Aerosol assisted CVD}

Aerosol assisted CVD is a variation of the conventional CVD process whereby aerosol droplets are used to transport the precursor, with the aid of inert or reactive carrier gases [117]. This has advantages over traditional CVD processes as the precursor does not need to be volatile, just soluble in any solvent that can be made into an aerosol [118]. It combines the advantages of both conventional CVD and spray pyrolysis processes [119]. In work conducted using a silicon based elastomer, AACVD was found to produce a highly developed microstructure in comparison to the flat surface created from dip coating, resulting in a contact angle of $165^{\circ}$ compared to $95^{\circ}$ [120]. In this work by Crick et al.[120] the AACVD sample was found to limit the attachment of bacteria following an hour long submersion in both E. coli and S. aureus compared to both the dip coated surface and an uncoated glass surface.

\subsection{Plasma deposition}

Plasma enhanced CVD is a chemical vapour deposition process whereby the chemical reaction is not initiated thermally, but through the formation of plasma through the use of RF or microwaves [76]. Differing from sputtering techniques in which the coating material is introduced as a solid, CVD use gaseous precursors [76]. It uses the energy of a plasma discharge to deposit a coating on a surface [114]. It is a uniform, reproducible an tunable means of treating a wide range of substrates and geometries [84]. It can be used for the synthesis of organic coatings in which monomers are activated in the plasma phase which allows the growth of materials close to the chemical composition of the monomer [114]. The synthesised materials are commonly referred to as plasma polymers (pp) and have been found to be useful in a number of different applications due to their good adherence to a surface as well as their high level of crosslinking and branching [84]. Plasma CVD has the ability to implement additional atoms into a coating, for example the addition of silicon containing precursors and oxygen to the working gas can be used to create a DLC-Si-O coating [76]. Disadvantages of the use of plasma CVD coatings is their reduced density and weaker adherence to the surface [76].

\subsection{Atmospheric plasma deposition}

As plasma is defined as a fully or partially ionised gas, atmospheric plasma refers to such a media that is developed at atmospheric pressure [114]. Atmospheric plasma deposition methods have advantages over vacuum techniques as they avoid the use of expensive pumping systems and having to build complex transfer chambers from air to vacuum with a high pressure gap [114].

It was found that an AP Liquid Deposition PEG coated surface significantly reduced the adsorption of bovine serum albumin (BSA) [a protein] by $90 \%$ compared to a bare $\mathrm{Si}$ surface, independent of plasma power [84]. Protein (BSA) adsorption reduction on an AP CVD PEG coated surface was found to increase with decreasing plasma power, from a 50 to $85 \%$ reduction in protein adsorption [84].

\section{Diamond like carbon (DLC)}

Hydrogenated amorphous carbon, also called diamond like carbon (DLC) has been investigated as a possible anti-fouling coating material [121]. DLC has attracted attention due to good thermal conductivity, corrosion resistance, very smooth surface and hardness 
[122]. In addition, the use of DLC coatings has been approved for use in the food industry by the FDA due to its atoxicity and corrosion resistance [122]. Carbon-carbon bonds can be either the near-planar trigonal $\left(\mathrm{sp}^{2}\right)$ found in graphite or the tetragonal $\left(\mathrm{sp}^{3}\right)$ form present in diamond [123]. DLC has a combination of both types of bonding, with its characteristics determined by the $\mathrm{sp}^{3}: \mathrm{sp}^{2}$ ratio. DLC also contains hydrogen in percentages ranging from just a few percent to in the region of 50\% [124]. The hydrogen in DLC is important in providing a number of key properties including stabilising the network and preventing it collapsing into a graphite phase.

There are a number of techniques that can be used to deposit DLC on a surface including: Direct ion beam deposition, pulsed laser ablation, filtered cathode arc deposition, magnetron sputtering, RF plasma-activated chemical vapour deposition, plasma source ion implantation and deposition [123]. The deposition of the DLC coating onto a surface will influence the behaviour that the coating exhibits [124]. Diamond like carbon has been used in the research or anti-fouling materials for a number of different industries, including medical implants [125] and food processing equipment [122]. It has been found to be able to reduce the adhesion of both whey protein and calcium phosphate adhesion in batch processes [75]. However, in the work done by Beuf [112] DLC was found not to have any significant reduction in fouling and also did not clean as well as native stainless steel.

\subsection{Modified DLC}

The amorphous nature of DLC allows the addition of additional elements, such as Si, F, N, $\mathrm{O}$, into the coating whilst maintaining the amorphous structure [121]. It has been found that the introduction of these additional elements into the DLC structure can be an effective method to reduce fouling [126]. Modified DLC coatings are usually produced using magnetron sputtering techniques or by plasma enhanced chemical vapour deposition (PECVD) [126]. The addition of both $\mathrm{N}$ and Si to DLC coatings has been performed to evaluate the effect that the coatings had on bacterial adhesion [127]. Liu et al. [127] evaluated two levels of both $\mathrm{N} \& \mathrm{Si}$ in the DLC surface on the adhesion in a shaken container over an hour long period. They found that the modified DLC coatings performed better than pure DLC in regards to limiting bacterial adhesion to the surface. The $\mathrm{N}$ doped DLC coating was found to out-perform the Si based coatings, with a reduction of adhesion of $89.7 \%$ found in the $2 \% \mathrm{~N}$ sample compared to the best performing Si doped sample's $38.5 \%$. A good correlation was found between the electron donor component of surface energy and the level of cellular attachment to the surface. This identified a trend of decreased attachment with increasing $\gamma^{-}$, which contrasts a number of other studies showing the opposite trend. However, the different coatings also produced a different level of roughness on the surface - with a strong correlation found between the number of adhering cells and the surface roughness.

Fluorinated DLC has also been found to have antibiological properties in regards to decreasing surface adhesion as well as increasing the removability of adhered cells [128, 129]. This became more pronounced as the proportion of $F$ content was increased in the coating, as it was found to reduce the surface energy of the surface [128]. The C-F bond is believed to decrease the dielectric constant and the cross-linked $\mathrm{C}-\mathrm{C}$ bonds contribute to the materials thermal stability [129]. Su [126] found that F-doped DLC reduced both bacterial adhesion and increase removal, improved with increasing F content (decreased SE) with the $39 \%$ w.t. sample performing the best $(67 \%$ reduced adhesion \& $32 \%$ increased removal compared to DLC). In addition to the decrease in surface energy with increasing fluorine content [128], structure of the film coatings also became more like a polymer structure than diamond like [129]. 
In addition to experiments looking at fluorinated $\mathrm{DLC}, \mathrm{Su}$ 's [126] $\mathrm{PhD}$ thesis reviewed a number of different types of modified DLC coatings. The experiments carried out for this work were conducted using the various DLC coatings and evaluating the degree of bacterial adhesion. The experimental work was conducted in stagnate conditions over a range of contact times from 1 to 18 hours. The various DLC coatings tested during the $\mathrm{PhD}$ [126], included Si-N, F, B, Ti and $\mathrm{Si}_{-} \mathrm{O}_{\mathrm{x}}$, were all identified as being able to reduce the adhesion of bacteria to a surface. The boron doped DLC was found to be most effective at the highest dose rate trialled $(9.5 \%)$ with the reduced total bacterial adhesion of $70 \%$ of the pure DLC coating. In addition, the B-DLC coating was found to increase the removal rate of bacteria by $164 \%$ compared to the pure DLC coating. The results exhibited by the boron doped DLC was linked to the surface energy, with increasing boron content leading to a lower surface energy and decrease in bacterial adhesion [126]. A similar trend was exhibited with the Ti-doped DLC coating trialled as part of the work of Su [126], with an increasing content of $\mathrm{Ti}$ resulting with a decrease in the level of bacterial adhesion (the best performing $66 \%$ better than pure DLC). However, unlike the B-DLC coating, the surface energy of the Ti-DLC coating remained relatively unchanged with the alteration to the level of titanium in the coating. A trend was identified in the electron donor component of the surface energy, with an increase in the $\mathrm{\gamma}$ - found to correlate with the increase in Ti content, and subsequent decrease in cell adhesion.

The Fraunhofer Institute in Germany has been investigating a number of different antifouling techniques for a number of years. Among the different coatings developed are SICAN (C:H:Si) and SICON® (C:H:Si:O), which are DLC based coatings comprising Silicon. These coatings have been used in a number of different experiments to identify their resistance to fouling. This includes an investigation carried out to identify whether the coatings were able to reduce the accumulation of both protein and minerals in a simulated milk ultrafiltrate with whey protein isolate added [130]. In this work, Boxler et al. [130] used a pilot scale facility to pass their milk based fluid through a plate heat exchanger over a 2 hour period at $85^{\circ} \mathrm{C}$. In their work they found that the formation of the initial fouling layer, subsequent build-up and composition of the deposit were affected by the surface energetic properties, in particular the electron-donor component $\left(\mathrm{\gamma}^{-}\right)$which showed a polynomial function with protein adhesion (curve depicting best $\gamma$ - as being mid-range for the experiments conducted). The SICAN coating was found to have the highest level of fouling mitigation of the various PECVD DLC coatings trialled in the study.

However, work has been done looking at doped-DLC coatings identifying no benefit to their use over stainless steel [1]. One constraint of interpreting this research is that the compounds used to dope the DLC are not disclosed in the publication. The results that Patel et al. [1] were initially promising at the laboratory scale where they found that for whey protein isolate (WPI) fouling was reduced by $35-40 \%$ compared to stainless steel over a 120 minutes trial period. However, when this period was extended to 480 minutes the reduction in fouling on the doped-DLC surface reduced to less than $15 \%$. At a full pilot scale even the slight benefit seen in the laboratory scale was lost, with the doped-DLC sample not performing as well as the stainless steel control surfaces. In addition to WPI, Patel et al. [1] performed testing on raw milk where they found only a slight difference at a pilot scale and no significant difference between the doped-DLC samples and stainless steel at the pilot scale. As well as looking at initial adhesion, they also investigated the removal of foulants during the cleaning process where they found no significant difference between the control and the DLC surfaces. These results lead to Patel et al. [1] stating that they found no commercial benefit from using surface modification to reduce fouling in processing conditions. The testing conditions used in these trials were more robust than a number of others in literature as they used full scale processing equipment, processing conditions and used times closer to commercial run times. 


\section{Liquid infused surfaces}

Liquid infused structures steam from yet another biomimetic related idea, the pitcher plant [131]. The pitcher plant has a water film that is locked into its surface under humid conditions [132]. The water film causes insects to aquaplane when they step on the wetted pitcher rim and results in the insects falling into the pitcher plant [133] as the water repels the oil on the insects feet [134]. This action has attracted attention, in particular in the area of antifouling coatings. It has advantages over the lotus-inspired surfaces, which rely on air as a lubricating fluid and tend to fail when the air escapes under conditions involving high temperatures, pressure, humidity and when exposed to low surface tension liquids [28], unlike the liquid infused surfaces.

Slippery liquid-infused porous surfaces, or SLIPS, consist of a film of lubricating liquid that is locked within the micro/nano-porous substrate. The lubricating liquid provides an ultra-smooth, continuous and chemically homogeneous interface that presents a slippery surface for a range of different fluids [28]. The lubricating fluid is stabilised by the capillary forces arising from the micro-structured texture [135]. There are three key criteria in designing a stable SLIPS: i) the chemical affinity between the lubricating fluid and the solid should be higher than that between the solid and the bulk fluid; ii) the solid should be roughened to increase the surface area for adhesion and immobilization of the lubricating fluid; iii) the lubricating fluid and bulk fluid should be largely immiscible [56].

The molecularly smooth and chemically homogenous lubricating liquid provides a low contact angle hysteresis (typically $<2^{\circ}$ ) and a low sliding angle [136]. The liquid plays a similar role to air pockets created in the lotus effect [134]. However, it has advantages over the air pockets in the fact that it can withstand pressures and is effective against destabilisation resulting from organic solvents [131]. Wong et al. [131], while investigating the properties of SLIPS, found that the surfaces' ability to repel both water and liquid hydrocarbons was stable when subjected to pressures of 676 atm. By choosing lubricating fluids that are immiscible with both oils and water, SLIPS can exhibit omniphobic properties [134]. One of the biggest weaknesses of the liquid infused porous surfaces is their durability [134]. Over time, the lubricating fluid may be lost due to evaporation or due to a high shear environment, compromising the capabilities of the surface [131]. Thus, choosing an appropriate lubricating fluid with a minimal evaporation rate or enhanced viscosity to minimise losses is advantageous, or alternatively a fluid reservoir can be used to enable self-replenishment of the lubricating fluid. The surfaces are designed to be selfhealing, with the lubricating fluid flowing to any damaged area via surface energy driven capillary action [137]. It has been found that uniform nanostructured surfaces provide a superior performance in high simulated shear conditions compared to hierarchical or microstructured surfaces [28]. This is due to the lubricating fluid creating a stable smooth overcoating until the thickness of the lubricating layer becomes comparable to the nanoscale features. So despite the nanotextured surface in the study of Kim et al. [28] losing more lubricant than the hierarchical structure studied, the quantity of liquid needed to maintain the SLIPS capabilities is lower.

The loss of lubricating fluid in higher shear environments does not necessarily rule out these surfaces, with the potential use of the lubricant as a sacrificial fluid. As a sacrificial liquid, the lubricant could be used to facilitate the processing of a fluid by reducing fouling and product losses. In this situation, the lubricant would have to be a liquid that does not negatively affect the quality of the product as the lost lubricant would end up in the product. One method to assist with the replenishment of a lubricating fluid is the inclusion of a vascular-like system [138]. In the work of Howell and others [138] they found that a vascular system built into a liquid infused surface was able to continuously replenish the depleted lubricating liquid, maintaining the antifouling properties of the surface over time. 
This type of system would utilise a reservoir to replenish the vascular system. Depending on the surface tension of the lubricant, the porous solid can be either a high or low energy surface [139]. This influences the activation barrier for nucleation to occur on the surface, with an impregnating lubricant with a low surface tension resulting in a high activation barrier and vice versa.

Micro-textured surfaces have a critical contact angle below which the lubricating liquid can impregnate the texture and remain held by the capillary forces [140]. It can be calculated using the Equation 2 below:

$$
\theta_{c}=\cos ^{-1}[(1-\emptyset) /(r-\emptyset)]
$$

The equation calculates the critical contact angle using the fraction of projected area of the textured surface that is occupied by the solid $(\Phi)$ and the ratio of total surface area of the textured surface to its projected area (r) [140]. Liquid infused surfaces have been created on a wide range of different materials including: polymers [133], stainless steel [140] and glass. These liquid infused surfaces have been applied to a number of different process fluids to test their repelling qualities. These include simple fluids through to complex fluids including blood [140], SLIPS has been used to investigate bacterial adhesion to the liquid infused surface [141]. In this work, Epstein et al. [141] identified that the modified surface was capable of preventing between $96-99 \%$ of common bacterial biofilms from attaching over a 7 days period in low flow conditions. The authors explored a number of different biofilm forming bacteria species including E.coli and S.aureus. In addition, the liquid infused surface was stable when submerged under extreme $\mathrm{pH}$, salinity and UV exposure. The surface that was used by Epstein et al. [141] was composed of a porous PTFE substrate or a fluro-silanised Si wafer, which was then infused with the lubricating fluid. Essentially the SLIPS surface prevents bacterial adhesion due to the lubricating liquid preventing the bacteria coming in contact with the solid below [142]. Additional studies have looked at liquid infused surfaces and bacterial adhesion, with a reduction in adhesion of both S.aureus and E.coli found to be at least 3 orders of magnitude compared to non-SLIPS surfaces [138]. Liquid-impregnated surfaces have been used to investigate their ability to resist deposits of calcium sulphate forming [139]. In this work, Subramanyam et al. [139] used ion etching to texture a silicon surface and coating it with octadecyltrichlorosilane, to lower its surface energy, and then impregnated the surface with different lubricating fluids. They identified that the surface tension and spreading coefficient of the lubricant had a profound effect on the surface properties and subsequent adhesion. All of their impregnated surfaces were identified as having a lower nucleation rate and thus a lowering the mass of calcium sulphate deposits, with a 10-fold reduction found in adhesion for one of the surfaces trialled. In addition to the silicon based surface, Subramanyam et al. [139] also developed a liquidimpregnated surface using stainless steel as the substrate, textured using simple sandblasting. They found that there was a reduction in deposits formed and that those formed could be easily washed away with low flow water.

SIPS has also been applied to investigate ice adhesion to surfaces [143, 144]. In their work, Kim et al. [143] developed a liquid infused porous surface using aluminium with the electrodeposition of highly textured polypyrrole, followed by fluorination and then infiltration of the lubricant. The found that the SLIPS suppressed the formation of ice and was also found to be effective at removing condensing moisture. The degree of the ice reduction and adhesion strength on the surface was found to be an order of magnitude greater than other state-of-the-art materials that were tested and two orders of magnitude lower than bare aluminium. The application of LiquiGlide to containers to reduce adhesion of products is one of the company's leading applications. This is done by applying an aerosol coating of wax and ethanol to the surface of the container. The ethanol evaporates off, leaving a porous wax coating on the surface of the container. An oil is then added to the 
container and is infused into the porous wax matrix. Residue oil is then removed from the surface leaving a liquid infused porous surface that is capable of preventing the adhesion of various materials that are filled into the container.

\section{Ultrasonics}

Ultrasound is the use of soundwaves with a frequency in excess of human hearing, $20 \mathrm{kHz}$ [145]. The application of ultrasound in the food industry can be divided into two: low energy, using frequencies above $100 \mathrm{kHz}$ at intensities below $1 \mathrm{Wcm}^{-2}$, and high energy ultrasound, using frequencies between 20 and $500 \mathrm{kHz}$ as well as intensities higher than $1 \mathrm{Wcm}^{-2}$ [145]. Whereas low energy ultra sound is used for non-invasive monitoring, high energy ultrasound is used to influence the physical, mechanical and biochemical properties of food.The propagation of ultrasound through a biological media causes compression and decompression through the material which imparts a high amount of energy [146]. High energy ultrasound has been used as an alternative processing tool for a range of operations ranging from controlling microstructure, emulsification, defoaming, accelerating enzyme activity, freezing, thawing and microbial inactivation [145].

The chemical effect of ultrasound does not occur as a direct result of interactions with molecular species, rather from acoustic cavitation, which involves the formation, growth and collapse of cavities (bubbles) in liquids [147]. At a surface, the collapse of the bubbles results in asymmetric microjets that can cleanse a surface of contaminants [145]. In addition, it can prevent adhesion from occurring as it causes the surface to be constantly moving, making it difficult for fouling to occur.

Sonication is thought to increase nucleation and crystal growth rate in a saturated or supercooled material [148]. This can be used in processing to assist in the development of ice crystals. When ultrasound is used to enhance crystallisation there is the benefit of the prevention of encrustation of crystals on the cooling element [148]. This means that ultrasound can be used in freezing processes to reduce the adhesion of ice and the subsequent product losses that can occur due to ice adhesion to cooling elements. High energy ultrasound has also been used to disrupt/inactivate bacteria as well as deagglomerate bacterial flocs (clusters) through the effect of cavitation [149]. It has therefore been utilised as an alternative processing tool in the inactivation of microorganisms as it also has the advantage of not degrading the processing fluid, which can occur in thermal processes [150]. However, it is in combination with different techniques such as thermal processing that ultrasound can be used to reduce processing time due to accelerated food sterilisation [145].

\section{Microwave processing}

In contrast to traditional thermal processing techniques whereby energy is transferred by convection, conduction or radiation, microwave energy is transferred directly to a material through molecular interaction with the electromagnetic field [151]. One key attraction of microwave heating, in the context of this report, is that the process produces minimal fouling deposits as a result of eliminating heat transfer surfaces [152].

Microwaves are a part of the electromagnetic spectrum, with wavelengths from $1 \mathrm{~mm}$ to 1 $\mathrm{m}$ [151] and corresponding frequencies between 0.3 and $300 \mathrm{GHz}$ [153]. Microwaves can be reflected, absorbed and/or transmitted by a material, with reflection and absorption requiring the interaction between the electromagnetic field and the material [153]. The fundamental electrical property that describes the interaction between electromagnetic energy and material is the relative complex permittivity [154]. The relative complex 
permittivity, $\varepsilon^{*}$, is the permittivity of the material, $\varepsilon$, divided by the permittivity of free space, $\varepsilon 0$ [155]. It can be broken down into two components by the following equation:

$$
\varepsilon^{*}=\varepsilon^{\prime}-j \varepsilon^{\prime \prime}
$$

This interaction with the electromagnetic field can be broken down to how the material stores energy, the dielectric constant $\left(\varepsilon^{\prime}\right)$, and how it dissipates energy as heat, the dielectric loss factor $\left(\varepsilon^{\prime \prime}\right)$ [156]. These properties quantify the capacitive and conductive components of the dielectric response respectively [151]. The dielectric constant is dominated by polarisation (in particular dipolar rotation) while the loss factor is dominated by ionic conduction within the sample being examined [156]. In foods, water is the primary component responsible for dipolar rotation while salts are responsible for the ionic interactions [157]. The polarisation involves the short-range displacement of charge through both the formation and rotation of electric (or magnetic) dipoles, while conduction requires the (relatively) long range transport of charge [153]. Ionic loss is typically predominant at frequencies below $1 \mathrm{GHz}$ [158]. Whereas dipolar polarisation is typically more significant above $1 \mathrm{GHz}$, although it still influences the dielectric response of a material at lower frequencies as well [159]. The frequencies used are also of particular interest in regards to gaining an understanding of microwave heating [154]. This is due to specific frequencies, including $915 \mathrm{MHz} \& 2.45 \mathrm{GHz}$, being set aside for use in microwave ovens \& industrial microwave heating [160].

When water molecules are exposed to microwave radiation, the molecular dipoles try to align in the direction of the applied electromagnetic field [161]. As the applied field oscillates, the dipoles attempt to follow the oscillations, and the electromagnetic energy it transferred into thermal energy as a result of molecular friction and dielectric loss. The alternating electric field causes the charged ions to oscillate back and forth, resulting in heating due to the agitation caused by the ions bumping into other molecules [161]. The dielectric properties of a food material are dependent on its composition, especially that of water and minerals. In addition, the degree of freedom of those elements in the food material impacts the dielectric properties [154]. Ionic conduction at relatively low frequencies has a much greater ability to generate heat than dipolar rotation, with ionic solutions heating faster than pure water [161].

Microwave heating is also affected by the relative freedom of components in a system, such as whether ions are bound [162] and the degree of freedom of the water molecules present. The dielectric properties of a material can change during processing due to physical and structural transformations [154]. As a result, the ability for microwaves to generate heat can vary during processing [151]. The penetration depth (dp) of microwave processing is commonly defined as the depth into a sample where the power has dropped to $1 / \mathrm{e}$ or $36.8 \%$ of its transmitted value [163]. The penetration depth is inversely proportional to the microwave frequency. Therefore microwave processing using a frequency of $915 \mathrm{MHz}$ have a higher penetration depth into a product than processing using a frequency of 2.45 $\mathrm{GHz}$ [164].

A number of advantages exist in the use of microwave heating including: it does not rely on the diffusion of heat from the surface so can apply rapid \& uniform heating of large volumes [151], selective heating of components possible [153], minimal come up time (CUT) required [152], energy saving due to the high degree of efficiency in microwave heating [165], One key disadvantage with most common microwave heating processes is the non-uniform heat distribution that can be generated that results in hot and cold spots[166]. This non-uniform heating is more common in solid food processing rather than in the heating of fluids [165].

Microwave drying offers the means to shorten the drying time of a product as well as improving the product quality compared to conventional drying processes [167]. In drying 
applications microwave processing has been found to reduce processing time due to the build-up of internal vapour pressure that drives out moisture of the product [161]. The improvement in product quality steams from the short processing time required, resulting in a decrease in the loss of heat sensitive compounds such as colours, nutrients and flavour [165].

Limitations of microwave drying processes include the possible development of scorching at the edges of a product due to the development of excessive heat at those points during the final stages of drying [168]. This is the result of the difficulty in controlling the final temperature of a product during microwave drying; unlike air drying where the product cannot exceed the temperature of the hot air. One method used to assist in overcoming the limitations of microwave drying or the limitation of other conventional drying techniques is the coupling of microwave drying with another drying method [167]. This includes the use of microwave (MW) assisted air drying, MW assisted vacuum drying, MW assisted freeze drying and MW assisted spouted bed drying. This microwave assisted drying can improve the drying efficiency of conventional drying processes and produce product with improved quality [168].

Microwave drying is considered to be very useful during the falling rate period. This is the period of the drying process when the diffusion is rate limiting, resulting in shrinkage and a reduced surface moisture content [168]. In microwave drying, due to the volumetric heating, the vapours are generated inside and an internal pressure gradient is created that forces the water out without any shrinkage occurring. However, this rapid mass transport can result in a phenomenon known as 'puffing', which may or may not be deemed desirable in a final product [167].

Microwave or microwave assisted processing has been applied to a number of different fluid and solid food systems [165]. This includes: the drying of honey [169], minimal processing of apple puree [170], avocado puree [171], and the pasteurisation of orange juice [172]. In these types of applications, microwave processing has been found to be capable of providing logarithmic reductions in the level of bacteria present in a product [173], the rapid inactivation of enzymes [174], and retaining antioxidant activity [175]. Industrial microwave processing systems are available including microwave dryers. These techniques have been adopted predominantly in Europe and Japan, with other countries such as the USA being more hesitant [152].

\section{Summary}

There are three key parameters that can affect adhesion in processing applications: the process fluid, the processing conditions and the surface that the fluid interacts with. The surface has the greatest scope for manipulation to try and control the undesirable adhesion of matter that results in fouling. Manipulation of the surface energy and surface topography of a material, both independently and collectively, have been proven to be effective methods for altering the rate of adhesion to a surface. Although this is an area of research gaining increasing attention, no silver bullet has been found that produces a surface that is durable and reduces adhesion universally for all species and applications. The key to developing a surface that is capable of controlling adhesion requires ensuring that it is suitable for processing applications, and thus can withstand the rigours of the shear stresses and cleaning regimes that are commonplace in processing industries. 


\section{References}

1. M. Jimenez, H. Hamze, A. Allion, G. Ronse, G. Delaplace, M. Traisnel, Antifouling stainless steel surface: competition between roughness and surface energy, in: Materials Science Forum, Trans Tech Publ, 2012, pp. 2523-2528

2. J.A. Barish, J.M. Goddard, Anti-fouling surface modified stainless steel for food processing, Food and Bioproducts Processing, 91 (2013) 352-361

3. J.S. Patel, B. Bansal, M.I. Jones, M. Hyland, Fouling behaviour of milk and whey protein isolate solution on doped diamond-like carbon modified surfaces, Journal of Food Engineering, 116 (2013) 413-421

4. M. Mauermann, U. Eschenhagen, T. Bley, J.-P. Majschak, Surface modificationsapplication potential for the reduction of cleaning costs in the food processing industry, Trends in Food Science \& Technology, 20 (2009) S9-S15

5. L. Gomes da Cruz, E.M. Ishiyama, C. Boxler, W. Augustin, S. Scholl, D.I. Wilson, Value pricing of surface coatings for mitigating heat exchanger fouling, Food and Bioproducts Processing, (2014)

6. J.A. Barish, J.M. Goddard, Stability of nonfouling stainless steel heat exchanger plates against commercial cleaning agents, Journal of Food Engineering, 124 (2014) 143-151

7. T. Mérian, J.M. Goddard, Advances in Nonfouling Materials: Perspectives for the Food Industry, Journal of agricultural and food chemistry, 60 (2012) 2943-2957

8. F. Podczeck, Investigations into the reduction of powder adhesion to stainless steel surfaces by surface modification to aid capsule filling, International Journal of Pharmaceutics, 178 (1999) 93-100

9. D. Gunn, Effect of surface roughness on the nucleation and growth of calcium sulphate on metal surfaces, Journal of Crystal Growth, 50 (1980) 533-537

10. J.F. Schumacher, M.L. Carman, T.G. Estes, A.W. Feinberg, L.H. Wilson, M.E. Callow, J.A. Callow, J.A. Finlay, A.B. Brennan, Engineered antifouling microtopographies-effect of feature size, geometry, and roughness on settlement of zoospores of the green alga Ulva, Biofouling, 23 (2007) 55-62

11. M.V. Graham, N.C. Cady, Nano and Microscale Topographies for the Prevention of Bacterial Surface Fouling, Coatings, 4 (2014) 37-59

12. Y. Engel, J.D. Schiffman, J.M. Goddard, V.M. Rotello, Nanomanufacturing of biomaterials, Materials Today, 15 (2012) 478-485

13. Biswas, I.S. Bayer, A.S. Biris, T. Wang, E. Dervishi, F. Faupel, Advances in topdown and bottom-up surface nanofabrication: Techniques, applications \& future prospects, Advances in colloid and interface science, 170 (2012) 2-27

14. A.K. Epstein, J. Aizenberg, Biomimetic nanostructured surfaces with designer mechanics and geometry for broad applications, in: MRS Proceedings, Cambridge Univ Press, 2009, pp. 1236-SS1209-1207

15. L. Li, V. Breedveld, D.W. Hess, Creation of superhydrophobic stainless steel surfaces by acid treatments and hydrophobic film deposition, ACS applied materials \& interfaces, 4 (2012) 4549-4556

16. J.F. Schumacher, N. Aldred, M.E. Callow, J.A. Finlay, J.A. Callow, A.S. Clare, A.B. Brennan, Species-specific engineered antifouling topographies: correlations between the settlement of algal zoospores and barnacle cyprids, Biofouling, 23 (2007) 307317

17. P. Roach, D. Eglin, K. Rohde, C.C. Perry, Modern biomaterials: a review-bulk properties and implications of surface modifications, Journal of Materials Science: Materials in Medicine, 18 (2007) 1263-1277 
18. M.V. Graham, A.P. Mosier, T.R. Kiehl, A.E. Kaloyeros, N.C. Cady, Development of antifouling surfaces to reduce bacterial attachment, Soft Matter, 9 (2013) 6235-6244

19. M. Sarikaya, C. Tamerler, A.K.-Y. Jen, K. Schulten, F. Baneyx, Molecular biomimetics: nanotechnology through biology, Nature materials, 2 (2003) 577-585

20. B. Bhushan, E.K. Her, Fabrication of superhydrophobic surfaces with high and low adhesion inspired from rose petal, Langmuir, 26 (2010) 8207-8217

21. F. Guittard, T. Darmanin, Recent Advances in the Potential Applications of Bioinspired Superhydrophobic Materials, Journal of Materials Chemistry A, (2014)

22. O.-U. Nimittrakoolchai, S. Supothina, Deposition of organic-based superhydrophobic films for anti-adhesion and self-cleaning applications, Journal of the European Ceramic Society, 28 (2008) 947-952

23. S. Nishimoto, B. Bhushan, Bioinspired self-cleaning surfaces with superhydrophobicity, superoleophobicity, and superhydrophilicity, Rsc Advances, 3 (2013) 671-690

24. M. Sun, C. Luo, L. Xu, H. Ji, Q. Ouyang, D. Yu, Y. Chen, Artificial lotus leaf by nanocasting, Langmuir, 21 (2005) 8978-8981

25. M. Qu, G. Zhao, X. Cao, J. Zhang, Biomimetic fabrication of lotus-leaf-like structured polyaniline film with stable superhydrophobic and conductive properties, Langmuir, 24 (2008) 4185-4189

26. G.D. Bixler, B. Bhushan, Bioinspired rice leaf and butterfly wing surface structures combining shark skin and lotus effects, Soft Matter, 8 (2012) 11271-11284

27. K. Liu, X. Yao, L. Jiang, Recent developments in bio-inspired special wettability, Chemical Society Reviews, 39 (2010) 3240-3255

28. P. Kim, M.J. Kreder, J. Alvarenga, J. Aizenberg, Hierarchical or not? Effect of the length scale and hierarchy of the surface roughness on omniphobicity of lubricantinfused substrates, Nano letters, 13 (2013) 1793-1799

29. C. Mao, C. Liang, W. Luo, J. Bao, J. Shen, X. Hou, W. Zhao, Preparation of lotusleaf-like polystyrene micro- and nanostructure films and its blood compatibility, Journal of Materials Chemistry, 19 (2009) 9025-9029

30. K.K. Chung, J.F. Schumacher, E.M. Sampson, R.A. Burne, P.J. Antonelli, A.B. Brennan, Impact of engineered surface microtopography on biofilm formation of Staphylococcus aureus, Biointerphases, 2 (2007) 89-94

31. S.T. Reddy, K.K. Chung, C.J. McDaniel, R.O. Darouiche, J. Landman, A.B. Brennan, Micropatterned surfaces for reducing the risk of catheter-associated urinary tract infection: an in vitro study on the effect of sharklet micropatterned surfaces to inhibit bacterial colonization and migration of uropathogenic Escherichia coli, Journal of Endourology, 25 (2011) 1547-1552

32. Q. Zhao, Y. Liu, C. Wang, S. Wang, H. Müller-Steinhagen, Effect of surface free energy on the adhesion of biofouling and crystalline fouling, Chemical Engineering Science, 60 (2005) 4858-4865

33. M.E. Callow, R.L. Fletcher, The influence of low surface energy materials on bioadhesion - a review, International biodeterioration \& biodegradation, 34 (1994) 333-348

34. E. Lindner, A low surface free energy approach in the control of marine biofouling, Biofouling, 6 (1992) 193-205

35. Q. Zhao, C. Liu, Y. Liu, S. Wang, Bacterial and protein adhesion on Ni-P-PTFE coated surfaces, (2007)

36. Hamza, V.A. Pham, T. Matsuura, J.P. Santerre, Development of membranes with low surface energy to reduce the fouling in ultrafiltration applications, Journal of Membrane Science, 131 (1997) 217-227 
37. R. Baier, Substrata influences on adhesion of microorganisms and their resultant new surface properties, in, Wiley-Interscience, New York, 1980

38. P.J. Fryer, P.T. Robbins, I. Asteriadou, Current Knowledge in Hygienic Design: Can We Minimise Fouling and Speed Cleaning?, in: Advances in Food Process Engineering Research and Applications, Springer, 2013, pp. 209-227

39. W. Liu, P. Fryer, Z. Zhang, Q. Zhao, Y. Liu, Identification of cohesive and adhesive effects in the cleaning of food fouling deposits, Innovative Food Science \& Emerging Technologies, 7 (2006) 263-269

40. M.C. Michalski, S. Desobry, J. Hardy, Food materials adhesion: a review, Critical reviews in food science and nutrition, 37 (1997) 591-619

41. B. Bhandari, T. Howes, Relating the stickiness property of foods undergoing drying and dried products to their surface energetics, Drying Technology, 23 (2005) 781-797

42. R. Rosmaninho, L.F. Melo, Calcium phosphate deposition from simulated milk ultrafiltrate on different stainless steel-based surfaces, International Dairy Journal, 16 (2006) 81-87

43. C. Liu, Q. Zhao, Influence of surface-energy components of Ni-P-TiO2-PTFE nanocomposite coatings on bacterial adhesion, Langmuir, 27 (2011) 9512-9519

44. C.J. Van Oss, Interfacial forces in aqueous media, CRC press, 2006

45. C. Liu, Q. Zhao, The CQ ratio of surface energy components influences adhesion and removal of fouling bacteria, Biofouling, 27 (2011) 275-285

46. A.B. Kananeh, E. Scharnbeck, U. Kück, N. Räbiger, Reduction of milk fouling inside gasketed plate heat exchanger using nano-coatings, Food and Bioproducts Processing, $\mathbf{8 8}$ (2010) 349-356

47. K.R. Goode, K. Asteriadou, P.T. Robbins, P.J. Fryer, Fouling and cleaning studies in the food and beverage industry classified by cleaning type, Comprehensive Reviews in Food Science and Food Safety, 12 (2013) 121-143

48. E. Celia, T. Darmanin, E. Taffin de Givenchy, S. Amigoni, F. Guittard, Recent advances in designing superhydrophobic surfaces, Journal of colloid and interface science, 402 (2013) 1-18

49. A.B.D. Cassie, S. Baxter, Wettability of porous surfaces, Transactions of the Faraday Society, 40 (1944) 546-551

50. B.R. Bhandari, N. Datta, T. Howes, Problems associated with spray drying of sugarrich foods, Drying Technology, 15 (1997) 671-684

51. M. Miwa, A. Nakajima, A. Fujishima, K. Hashimoto, T. Watanabe, Effects of the surface roughness on sliding angles of water droplets on superhydrophobic surfaces, Langmuir, 16 (2000) 5754-5760

52. S.H. Yoon, N. Rungraeng, W. Song, S. Jun, Superhydrophobic and superhydrophilic nanocomposite coatings for preventing Escherichia coli K-12 adhesion on food contact surface, Journal of Food Engineering, 131 (2014) 135-141

53. M. Nosonovsky, B. Bhushan, Superhydrophobic surfaces and emerging applications: non-adhesion, energy, green engineering, Current Opinion in Colloid \& Interface Science, 14 (2009) 270-280

54. B. Bhushan, Fabrication Techniques Used for Structures with Superhydrophobicity, Self-Cleaning, Low Adhesion/Low Drag with Antifouling Properties, in: Biomimetics, Springer, 2012, pp. 67-78

55. L. Feng, S. Li, Y. Li, H. Li, L. Zhang, J. Zhai, Y. Song, B. Liu, L. Jiang, D. Zhu, Super-hydrophobic surfaces: from natural to artificial, Advanced materials, 14 (2002) 1857-1860

56. A.K. Epstein, T.-S. Wong, R.A. Belisle, E.M. Boggs, J. Aizenberg, Liquid-infused structured surfaces with exceptional anti-biofouling performance, Proceedings of the National Academy of Sciences, 109 (2012) 13182-13187 
57. H. Zhang, R. Lamb, J. Lewis, Engineering nanoscale roughness on hydrophobic surface-preliminary assessment of fouling behaviour, Science and Technology of Advanced Materials, 6 (2005) 236-239

58. Tiraferri, Y. Kang, E.P. Giannelis, M. Elimelech, Superhydrophilic thin-film composite forward osmosis membranes for organic fouling control: fouling behavior and antifouling mechanisms, Environmental science \& technology, 46 (2012) 11135 11144

59. S. Song, L. Jing, S. Li, H. Fu, Y. Luan, Superhydrophilic anatase TiO2 film with the micro- and nanometer-scale hierarchical surface structure, Materials Letters, 62 (2008) 3503-3505

60. V. Kumar, J. Pulpytel, G. Giudetti, H. Rauscher, F. Rossi, F. Arefi-Khonsari, Amphiphilic Copolymer Coatings via Plasma Polymerisation Process: Switching and Anti-Biofouling Characteristics, Plasma Processes and Polymers, 8 (2011) 373-385

61. J. Peng, Y. Su, Q. Shi, W. Chen, Z. Jiang, Protein fouling resistant membrane prepared by amphiphilic pegylated polyethersulfone, Bioresource Technology, 102 (2011) 2289-2295

62. C.S. Gudipati, J.A. Finlay, J.A. Callow, M.E. Callow, K.L. Wooley, The antifouling and fouling-release perfomance of hyperbranched fluoropolymer (HBFP)-poly (ethylene glycol)(PEG) composite coatings evaluated by adsorption of biomacromolecules and the green fouling alga ulva, Langmuir, 21 (2005) 3044-3053

63. S. Arifuzzaman, A.E. Özçam, K. Efimenko, D.A. Fischer, J. Genzer, Formation of surface-grafted polymeric amphiphilic coatings comprising ethylene glycol and fluorinated groups and their response to protein adsorption, Biointerphases, 4 (2009) FA33-FA44

64. Y. Wang, D.E. Betts, J.A. Finlay, L. Brewer, M.E. Callow, J.A. Callow, D.E. Wendt, J.M. DeSimone, Photocurable amphiphilic perfluoropolyether/poly (ethylene glycol) networks for fouling-release coatings, Macromolecules, 44 (2011) 878-885

65. Z. Yi, L.-P. Zhu, Y.-Y. Xu, Y.-F. Zhao, X.-T. Ma, B.-K. Zhu, Polysulfone-based amphiphilic polymer for hydrophilicity and fouling-resistant modification of polyethersulfone membranes, Journal of Membrane Science, 365 (2010) 25-33

66. D. Tsuchida, C. Kang, M. Okada, K. Matsumoto, T. Kawagoe, Ice formation process by cooling water-oil emulsion with stirring in a vessel, International journal of refrigeration, 25 (2002) 250-258

67. Banerjee, R.C. Pangule, R.S. Kane, Antifouling coatings: recent developments in the design of surfaces that prevent fouling by proteins, bacteria, and marine organisms, Advanced materials, 23 (2011) 690-718

68. A.B. Kananeh, E. Scharnbeck, D. Hartmann, Application of antifouling surfaces in plate heat exchanger for food production, in: International conference on Heat Exchanger Fouling and Cleaning VIII, Schladming, Austria, 2009

69. E. Sadeghinezhad, S.N. Kazi, A. Badarudin, M.N.M. Zubair, B.L. Dehkordi, C.S. Oon, A review of milk fouling on heat exchanger surfaces, Reviews in Chemical Engineering, 29 (2013) 169-188

70. S. Krishnan, C.J. Weinman, C.K. Ober, Advances in polymers for anti-biofouling surfaces, Journal of Materials Chemistry, 18 (2008) 3405-3413

71. J.W. Costerton, P.S. Stewart, E.P. Greenberg, Bacterial Biofilms: A Common Cause of Persistent Infections, science, 284 (1999) 1318-1322

72. W.G. Sawyer, K.D. Freudenberg, P. Bhimaraj, L.S. Schadler, A study on the friction and wear behavior of PTFE filled with alumina nanoparticles, Wear, 254 (2003) 573580

73. F.W. Billmeyer Jr, Textbook of polymer science in: New York, 1984 
74. B.A. Krick, J.J. Ewin, G.S. Blackman, C.P. Junk, W. Gregory Sawyer, Environmental dependence of ultra-low wear behavior of polytetrafluoroethylene (PTFE) and alumina composites suggests tribochemical mechanisms, Tribology International, 51 (2012) 42-46

75. R. Rosmaninho, O. Santos, T. Nylander, M. Paulsson, M. Beuf, T. Benezech, S. Yiantsios, N. Andritsos, A. Karabelas, G. Rizzo, Modified stainless steel surfaces targeted to reduce fouling-evaluation of fouling by milk components, Journal of Food Engineering, 80 (2007) 1176-1187

76. Santos, T. Nylander, R. Rosmaninho, G. Rizzo, S. Yiantsios, N. Andritsos, A. Karabelas, H. Müller-Steinhagen, L. Melo, L. Boulangé-Petermann, C. Gabet, A. Braem, C. Trägårdh, M. Paulsson, Modified stainless steel surfaces targeted to reduce fouling - surface characterization, Journal of Food Engineering, 64 (2004) 63-79

77. S. Armyanov, J. Georgieva, D. Tachev, E. Valova, N. Nyagolova, S. Mehta, D. Leibman, A. Ruffini, Electroless Deposition of Ni-Cu-P Alloys in Acidic Solutions, Electrochemical and solid-state letters, 2 (1999) 323-325

78. N. Rungraeng, Y.-C. Cho, S.H. Yoon, S. Jun, Carbon nanotubepolytetrafluoroethylene nanocomposite coating for milk fouling reduction in plate heat exchanger, Journal of Food Engineering, 111 (2012) 218-224

79. W. Chen, F. Li, G. Han, J. Xia, L. Wang, J. Tu, Z. Xu, Tribological behavior of carbon-nanotube-filled PTFE composites, Tribology Letters, 15 (2003) 275-278

80. N. Rungraeng, S. Jun, Carbon Nanotubes-Polytetrafluoroethylene Nanocomposite Coatings, Polymer Nanocomposite Coatings, (2013) 61

81. Q. Zhao, Y. Liu, C. Wang, Development and evaluation of electroless Ag-PTFE composite coatings with anti-microbial and anti-corrosion properties, Applied Surface Science, 252 (2005) 1620-1627

82. E. Ostuni, R.G. Chapman, R.E. Holmlin, S. Takayama, G.M. Whitesides, A survey of structure-property relationships of surfaces that resist the adsorption of protein, Langmuir, 17 (2001) 5605-5620

83. R.G. Chapman, E. Ostuni, S. Takayama, R.E. Holmlin, L. Yan, G.M. Whitesides, Surveying for surfaces that resist the adsorption of proteins, Journal of the American Chemical Society, 122 (2000) 8303-8304

84. B. Nisol, G. Oldenhove, N. Preyat, D. Monteyne, M. Moser, D. Perez-Morga, F. Reniers, Atmospheric plasma synthesized PEG coatings: non-fouling biomaterials showing protein and cell repulsion, Surface and Coatings Technology, 252 (2014) 126-133

85. D. Perera-Costa, J.M. Bruque, M.a.L. González-Martín, A.C. Gómez-García, V. Vadillo-Rodriguez, Studying the Influence of Surface Topography on Bacterial Adhesion using Spatially Organized Microtopographic Surface Patterns, Langmuir, 30 (2014) 4633-4641

86. J. Cui, Y. Ju, K. Liang, H. Ejima, S. Lörcher, K.T. Gause, J.J. Richardson, F. Caruso, Nanoscale engineering of low-fouling surfaces through polydopamine immobilisation of zwitterionic peptides, Soft Matter, 10 (2014) 2656-2663

87. S. Jiang, Z. Cao, Ultralow-Fouling, Functionalizable, and Hydrolyzable Zwitterionic Materials and Their Derivatives for Biological Applications, Advanced materials, 22 (2010) 920-932

88. M. Hess, R. Jones, J. Kahovec, T. Kitayama, P. Kratochvíl, P. Kubisa, W. Mormann, R. Stepto, D. Tabak, J. Vohlídal, Terminology of polymers containing ionizable or ionic groups and of polymers containing ions (IUPAC Recommendations 2006), Pure and Applied Chemistry, 78 (2006) 2067-2074 
89. H.-W. Chien, C.-C. Tsai, W.-B. Tsai, M.-J. Wang, W.-H. Kuo, T.-C. Wei, S.-T. Huang, Surface conjugation of zwitterionic polymers to inhibit cell adhesion and protein adsorption, Colloids and Surfaces B: Biointerfaces, 107 (2013) 152-159

90. W. Feng, S. Zhu, K. Ishihara, J.L. Brash, Protein resistant surfaces: Comparison of acrylate graft polymers bearing oligo-ethylene oxide and phosphorylcholine side chains, Biointerphases, 1 (2006) 50-60

91. Y. He, J. Hower, S. Chen, M.T. Bernards, Y. Chang, S. Jiang, Molecular simulation studies of protein interactions with zwitterionic phosphorylcholine self-assembled monolayers in the presence of water, Langmuir, 24 (2008) 10358-10364

92. H. Zhang, J. Zou, N. Lin, B. Tang, Review On Electroless Plating Ni-P Coatings For Improving Surface Performance Of Steel, Surface Review and Letters, (2014)

93. J. Novakovic, P. Vassiliou, K. Samara, T. Argyropoulos, Electroless NiP-TiO $<$ sub $>$ $2</$ sub $>$ composite coatings: Their production and properties, Surface and Coatings Technology, 201 (2006) 895-901

94. W. Chen, W. Gao, Y. He, A novel electroless plating of $\mathrm{Ni}-\mathrm{P}-\mathrm{TiO}<\mathrm{sub}>2</$ sub $>$ nano-composite coatings, Surface and Coatings Technology, 204 (2010) 2493-2498.

95. Q. Zhao, C. Liu, X. Su, S. Zhang, W. Song, S. Wang, G. Ning, J. Ye, Y. Lin, W. Gong, Antibacterial characteristics of electroless plating Ni-P-TiO2 coatings, Applied Surface Science, 274 (2013) 101-104

96. X.-P. Wang, Y. Yu, X.-F. Hu, L. Gao, Hydrophilicity of $\mathrm{TiO}<\mathrm{sub}>2</$ sub $>$ films prepared by liquid phase deposition, Thin Solid Films, 371 (2000) 148-152.

97. B. Li, B.E. Logan, The impact of ultraviolet light on bacterial adhesion to glass and metal oxide-coated surface, Colloids and Surfaces B: Biointerfaces, 41 (2005) 153161

98. Al-Janabi, M. Malayeri, H. Müller-Steinhagen, Minimization of CaSO4 deposition through surface modification, Heat transfer engineering, 32 (2011) 291-299

99. F. Siedenbiedel, J.C. Tiller, Antimicrobial polymers in solution and on surfaces: overview and functional principles, Polymers, 4 (2012) 46-71

100. P.N. Coneski, P.A. Fulmer, J.H. Wynne, Enhancing the fouling resistance of biocidal urethane coatings via surface chemistry modulation, Langmuir, 28 (2012) 7039-7048

101. R. Kumar, H. Münstedt, Silver ion release from antimicrobial polyamide/silver composites, Biomaterials, 26 (2005) 2081-2088

102. A.W. Smith, Biofilms and antibiotic therapy: is there a role for combating bacterial resistance by the use of novel drug delivery systems?, Advanced drug delivery reviews, 57 (2005) 1539-1550

103. M. Simões, L.C. Simões, M.J. Vieira, A review of current and emergent biofilm control strategies, LWT - Food Science and Technology, 43 (2010) 573-583

104. P.N. Coneski, M.H. Schoenfisch, Synthesis of nitric oxide-releasing polyurethanes with S-nitrosothiol-containing hard and soft segments, Polymer chemistry, 2 (2011) 906-913

105. J.C. Tiller, C.-J. Liao, K. Lewis, A.M. Klibanov, Designing surfaces that kill bacteria on contact, Proceedings of the National Academy of Sciences, 98 (2001) 5981-5985

106. J.W. Mayer, L. Eriksson, J.A. Davies, Ion implantation in semiconductors: silicon and germanium, (1970)

107. M. Dhillon, The effect of silver ion-implantation of stainless steel on bacterial adhesion and biofilm formation, in: Institute of Food, Nutrition and Human Health, Massey University, Palmerston North, 2012

108. H. Müller-Steinhagen, Q. Zhao, Investigation of low fouling surface alloys made by ion implantation technology, Chemical Engineering Science, 52 (1997) 3321-3332

109. Q. Zhao, B. Burnside, Dropwise condensation of steam on ion implanted condenser surfaces, Heat Recovery Systems and CHP, 14 (1994) 525-534 
110. Nejim, C. Jeynes, Q. Zhao, H. Muller-Steinhagen, Ion implantation of stainless steel heater alloys for anti-fouling applications, in: Ion Implantation Technology Proceedings, 1998 International Conference on, IEEE, 1999, pp. 869-872

111. Q. Zhao, Y. Liu, C. Wang, S. Wang, N. Peng, C. Jeynes, Reduction of bacterial adhesion on ion-implanted stainless steel surfaces, Medical engineering \& physics, 30 (2008) 341-349

112. M. Beuf, G. Rizzo, J. Leuliet, H. Müller-Steinhagen, S. Yiantsios, A. Karabelas, T. Benezech, Fouling and cleaning of modified stainless steel plate heat exchangers processing milk products, Heat Exchanger Fouling and Cleaning: Fundamentals and Applications, 14 (2003)

113. D. Quain, E. Storgårds, The extraordinary world of biofilms, PloS Biology, 5 (2009) 2458-2461

114. D. Merche, N. Vandencasteele, F. Reniers, Atmospheric plasmas for thin film deposition: A critical review, Thin Solid Films, 520 (2012) 4219-4236

115. R. Rosmaninho, F. Rocha, G. Rizzo, H. Müller-Steinhagen, L. Melo, Calcium phosphate fouling on TiN-coated stainless steel surfaces: Role of ions and particles, Chemical Engineering Science, 62 (2007) 3821-3831

116. R. Rosmaninho, G. Rizzo, H. Müller-Steinhagen, L. Melo, Deposition from a milk mineral solution on novel heat transfer surfaces under turbulent flow conditions, Journal of Food Engineering, 85 (2008) 29-41

117. X. Hou, K.L. Choy, Processing and Applications of Aerosol-Assisted Chemical Vapor Deposition, Chemical vapor deposition, 12 (2006) 583-596

118. R.G. Palgrave, I.P. Parkin, Aerosol assisted chemical vapour deposition of photochromic tungsten oxide and doped tungsten oxide thin films, Journal of Materials Chemistry, 14 (2004) 2864-2867

119. K. Choy, Chemical vapour deposition of coatings, Progress in materials science, 48 (2003) $57-170$

120. C.R. Crick, S. Ismail, J. Pratten, I.P. Parkin, An investigation into bacterial attachment to an elastomeric superhydrophobic surface prepared $<\mathrm{i}>$ via $</ \mathrm{i}>$ aerosol assisted deposition, Thin Solid Films, 519 (2011) 3722-3727

121. R. Hauert, A review of modified DLC coatings for biological applications, Diamond and Related Materials, 12 (2003) 583-589

122. C. Boxler, W. Augustin, S. Scholl, Fouling of milk components on DLC coated surfaces at pasteurization and UHT temperatures, Food and Bioproducts Processing, 91 (2013) 336-347

123. G. Dearnaley, J.H. Arps, Biomedical applications of diamond-like carbon (DLC) coatings: A review, Surface and Coatings Technology, 200 (2005) 2518-2524

124. C. Donnet, Recent progress on the tribology of doped diamond-like and carbon alloy coatings: a review, Surface and Coatings Technology, 100 (1998) 180-186

125. Soininen, E. Kaivosoja, T. Sillat, S. Virtanen, Y.T. Konttinen, V.M. Tiainen, Osteogenic differentiation on DLC-PDMS-h surface, Journal of Biomedical Materials Research Part B: Applied Biomaterials, (2014)

126. X. Su, Development and evaluation of anti-biofouling nano-composite coatings, in, University of Dundee, 2013

127. C. Liu, Q. Zhao, Y. Liu, S. Wang, E. Abel, Reduction of bacterial adhesion on modified DLC coatings, Colloids and Surfaces B: Biointerfaces, 61 (2008) 182-187

128. X. Su, Q. Zhao, S. Wang, A. Bendavid, Modification of diamond-like carbon coatings with fluorine to reduce biofouling adhesion, Surface and Coatings Technology, 204 (2010) 2454-2458 
129. M. Ishihara, T. Kosaka, T. Nakamura, K. Tsugawa, M. Hasegawa, F. Kokai, Y. Koga, Antibacterial activity of fluorine incorporated DLC films, Diamond and Related Materials, 15 (2006) 1011-1014

130. C. Boxler, W. Augustin, S. Scholl, Influence of surface modification on the composition of a calcium phosphate-rich whey protein deposit in a plate heat exchanger, Dairy Science \& Technology, 94 (2014) 17-31

131. T.-S. Wong, S.H. Kang, S.K. Tang, E.J. Smythe, B.D. Hatton, A. Grinthal, J. Aizenberg, Bioinspired self-repairing slippery surfaces with pressure-stable omniphobicity, Nature, 477 (2011) 443-447

132. H.F. Bohn, W. Federle, Insect aquaplaning: Nepenthes pitcher plants capture prey with the peristome, a fully wettable water-lubricated anisotropic surface, Proceedings of the National Academy of Sciences of the United States of America, 101 (2004) 14138-14143

133. L. Xiao, J. Li, S. Mieszkin, A. Di Fino, A.S. Clare, M.E. Callow, J.A. Callow, M. Grunze, A. Rosenhahn, P.A. Levkin, Slippery Liquid-Infused Porous Surfaces Showing Marine Antibiofouling Properties, ACS applied materials \& interfaces, 5 (2013) 10074-10080

134. M. Nosonovsky, Materials science: Slippery when wetted, Nature, 477 (2011) 412413

135. J.D. Smith, R. Dhiman, S. Anand, E. Reza-Garduno, R.E. Cohen, G.H. McKinley, K.K. Varanasi, Droplet mobility on lubricant-impregnated surfaces, Soft Matter, 9 (2013) 1772-1780

136. P.W. Wilson, W. Lu, H. Xu, P. Kim, M.J. Kreder, J. Alvarenga, J. Aizenberg, Inhibition of ice nucleation by slippery liquid-infused porous surfaces (SLIPS), Physical Chemistry Chemical Physics, 15 (2013) 581-585

137. C. Ishino, M. Reyssat, E. Reyssat, K. Okumura, D. Quere, Wicking within forests of micropillars, EPL (Europhysics Letters), 79 (2007) 56005

138. C. Howell, T.L. Vu, J.J. Lin, S. Kolle, N. Juthani, E. Watson, J.C. Weaver, J. Alvarenga, J. Aizenberg, Self-replenishing vascularized fouling-release surfaces, ACS applied materials \& interfaces, (2014)

139. S.B. Subramanyam, G. Azimi, K.K. Varanasi, Designing Lubricant-Impregnated Textured Surfaces to Resist Scale Formation, Advanced Materials Interfaces, 1 (2014)

140. K.S. Khalil, S.R. Mahmoudi, N. Abu-dheir, K.K. Varanasi, Active surfaces: Ferrofluid-impregnated surfaces for active manipulation of droplets, Applied Physics Letters, 105 (2014) 041604

141. A.K. Epstein, D. Hong, P. Kim, J. Aizenberg, Biofilm attachment reduction on bioinspired, dynamic, micro-wrinkling surfaces, New Journal of Physics, 15 (2013) 095018

142. S.Y.-E. Tan, S.C. Chew, S.Y.-Y. Tan, M. Givskov, L. Yang, Emerging frontiers in detection and control of bacterial biofilms, Current opinion in biotechnology, 26 (2014) 1-6

143. P. Kim, T.-S. Wong, J. Alvarenga, M.J. Kreder, W.E. Adorno-Martinez, J. Aizenberg, Liquid-infused nanostructured surfaces with extreme anti-ice and anti-frost performance, ACS Nano, 6 (2012) 6569-6577

144. S.B. Subramanyam, K. Rykaczewski, K.K. Varanasi, Ice adhesion on lubricantimpregnated textured surfaces, Langmuir, 29 (2013) 13414-13418

145. T. Awad, H. Moharram, O. Shaltout, D. Asker, M. Youssef, Applications of ultrasound in analysis, processing and quality control of food: A review, Food Research International, 48 (2012) 410-427

146. J. Mason, F. Chemat, M. Vinatoru, The extraction of natural products using ultrasound or microwaves, Current Organic Chemistry, 15 (2011) 237-247 
147. K.S. Suslick, The chemical effects of ultrasound, Scientific American, 260 (1989) 8086

148. F. Chemat, H. Zill e, M.K. Khan, Applications of ultrasound in food technology: Processing, preservation and extraction, Ultrasonics Sonochemistry, 18 (2011) 813835

149. E. Joyce, S. Phull, J. Lorimer, T. Mason, The development and evaluation of ultrasound for the treatment of bacterial suspensions. A study of frequency, power and sonication time on cultured $<\mathrm{i}>$ Bacillus $</ \mathrm{i}>$ species, Ultrasonics Sonochemistry, 10 (2003) 315-318

150. P. Piyasena, E. Mohareb, R. McKellar, Inactivation of microbes using ultrasound: a review, International journal of food microbiology, 87 (2003) 207-216

151. E.T. Thostenson, T.W. Chou, Microwave processing: fundamentals and applications, Composites Part A: Applied Science and Manufacturing, 30 (1999) 1055-1071

152. J. Ahmed, H.S. Ramaswamy, Microwave pasteurization and sterilization of foods, Food Science And Technology-New York-Marcel Dekker-, 167 (2004) 691

153. D.E. Clark, W.H. Sutton, Microwave processing of materials, Annual Review of Materials Science, 26 (1996) 299-331

154. J. Smith, The assessment of structure and component mobility of Mozzarella cheese, in: Department of Food Science \& Technology, Massey University, Palmerston North, 2013

155. S.O. Nelson, Dielectric properties of agricultural products: measurements and applications, IEEE Transactions on Electrical Insulation, 26 (1991) 845-869

156. J. Smith, A. Carr, M. Golding, D. Reid, L. Zhang, Assessing the use of dielectric spectroscopy to analyse calcium induced compositional and structural changes in a model cheese, Procedia Food Science, 1 (2011) 1833-1840

157. M.A. Rao, S.S. Rizvi, A.K. Datta, J. Ahmed, Engineering properties of foods, CRC Press, 2014

158. E. Nyfors, P. Vainikainen, Industrial microwave sensors, Artech House Norwood (MA, USA), 1989

159. S. Ryynänen, The electromagnetic properties of food materials: a review of the basic principles, Journal of Food Engineering, 26 (1995) 409-429

160. Herve, J. Tang, L. Luedecke, H. Feng, Dielectric properties of cottage cheese and surface treatment using microwaves, Journal of Food Engineering, 37 (1998) 389-410

161. H. Feng, Y. Yin, J. Tang, Microwave drying of food and agricultural materials: basics and heat and mass transfer modeling, Food Engineering Reviews, 4 (2012) 89-106

162. R.V. Decareau, R.A. Peterson, Microwave processing and engineering, VCH, 1986

163. M. Venkatesh, G. Raghavan, An overview of dielectric properties measuring techniques, Canadian biosystems engineering, 47 (2005) 15-30

164. C. Tong, R. Lentz, J. Rossen, Dielectric properties of pea puree at $915 \mathrm{MHz}$ and 2450 $\mathrm{MHz}$ as a function of temperature, Journal of food science, 59 (1994) 121-122

165. C. Salazar-González, M.F. San Martín-González, A. López-Malo, M.E. Sosa-Morales, Recent studies related to microwave processing of fluid foods, Food and bioprocess technology, 5 (2012) 31-46

166. R. Vadivambal, D. Jayas, Non-uniform temperature distribution during microwave heating of food materials - A review, Food and bioprocess technology, 3 (2010) 161171

167. M. Zhang, J. Tang, A. Mujumdar, S. Wang, Trends in microwave-related drying of fruits and vegetables, Trends in Food Science \& Technology, 17 (2006) 524-534

168. S. Chandrasekaran, S. Ramanathan, T. Basak, Microwave food processing-A review, Food Research International, 52 (2013) 243-261 
169. Z.-W. Cui, L.-J. Sun, W. Chen, D.-W. Sun, Preparation of dry honey by microwavevacuum drying, Journal of Food Engineering, 84 (2008) 582-590

170. P.A. Picouet, A. Landl, M. Abadias, M. Castellari, I. Viñas, Minimal processing of a Granny Smith apple purée by microwave heating, Innovative Food Science \& Emerging Technologies, 10 (2009) 545-550

171. R.I. Guzmán-Gerónimo, M.G. López, L. Dorantes-Alvarez, Microwave processing of avocado: Volatile flavor profiling and olfactometry, Innovative Food Science \& Emerging Technologies, 9 (2008) 501-506

172. Fratianni, L. Cinquanta, G. Panfili, Degradation of carotenoids in orange juice during microwave heating, LWT-Food Science and Technology, 43 (2010) 867-871

173. S. Tajchakavit, H. Ramaswamy, P. Fustier, Enhanced destruction of spoilage microorganisms in apple juice during continuous flow microwave heating, Food Research International, 31 (1998) 713-722

174. K.N. Matsui, J.A.W. Gut, P.V. De Oliveira, C.C. Tadini, Inactivation kinetics of polyphenol oxidase and peroxidase in green coconut water by microwave processing, Journal of Food Engineering, 88 (2008) 169-176

175. M. Igual, E. García-Martínez, M. Camacho, N. Martínez-Navarrete, Effect of thermal treatment and storage on the stability of organic acids and the functional value of grapefruit juice, Food Chemistry, 118 (2010) 291-299 